\title{
AVALIAÇÃO DA RESISTÊNCIA DE VARIEDADES DE CANA-DE-AÇÚCAR AO RAQUITISMO-DA-SOQUEIRA COM BASE NA TAXA DE COLONIZAÇÃO DOS COLMOS POR Leifsonia xyli subsp. xyli
}

\section{Patrícia Benites Ros}

Dissertação apresentada à Escola Superior de

Agricultura “Luiz de Queiroz”, Universidade de São Paulo, para obtenção do título de Mestre em Ciências, Área de Concentração: Fisiologia e Bioquímica de Plantas.

P I R A C I C A B A

Estado de São Paulo - Brasil

Agosto - 2004 


\title{
AVALIAÇÃO DA RESISTÊNCIA DE VARIEDADES DE CANA-DE-AÇÚCAR AO RAQUITISMO-DA-SOQUEIRA COM BASE NA TAXA DE COLONIZAÇÃO DOS COLMOS POR Leifsonia xyli subsp. xyli
}

\section{Patrícia Benites Ros}

\author{
Bióloga
}

Orientador: Prof. Dr. LUIZ ANTONIO GALLO

Dissertação apresentada à Escola Superior de

Agricultura “Luiz de Queiroz”, Universidade de São Paulo, para obtenção do título de Mestre em Ciências, Área de Concentração: Fisiologia e Bioquímica de Plantas.

P I R A C I C A B A

Estado de São Paulo - Brasil

Agosto - 2004 
Dados Internacionais de Catalogação na Publicação (CIP)
DIVISÃO DE BIBLIOTECA E DOCUMENTAÇÃO - ESALQ/USP

Ros, Patrícia Benites

Avaliação da resistência de variedades de cana-de-açúcar ao raquitismo-da-soqueira com base na taxa de colonização dos colmos por Leifsonia xyli subsp. xyli / Patrícia Benites Ros. - - Piracicaba, 2004.

58 p. : il.

Dissertação (mestrado) - - Escola Superior de Agricultura Luiz de Queiroz, 2004.

Bibliografia.

1. Bactérias fitopatogênicas 2. Cana-de-açúcar 3. Raquitismo-das-soqueiras Resistência genética vegetal I. Título

CDD 633.61

"Permitida a cópia total ou parcial deste documento, desde que citada a fonte - O autor" 


\section{Ao meu Deus que me sustentou em todos os momentos}

A minha mãe Roseli, por sempre colocar os filhos como prioridade em sua vida; pelo amor, por ser meu porto seguro e por estar comigo em toda e qualquer circunstância.

Ao meu pai Antônio Carlos por sempre estar torcendo por mim, vibrando com cada conquista.

As minhas irmãs Paula e Priscila pela preocupação, atenção e amor.

A minha avó Laura pelo amor incondicional, e por tantas renúncias que fez a favor dos filhos e netos.

A minha tia Leni pela evidente satisfação em ter uma sobrinha estudando na ESALQ.

A minha sobrinha Ana Luisa e demais familiares pelo carinho e apoio.

A meus familiares que infelizmente partiram antes do término desse trabalho, na certeza que iremos ainda nos encontrar.

DEDICO

A Guilherme Lagazzi pelo companheirismo, amor e amizade. 


\section{AGRADECIMENTOS}

- Ao Prof Dr. Luiz Antonio Gallo pela amizade, orientação, atenção, e participação efetiva no andamento dessa pesquisa;

- Ao Dr. Éder Antonio Giglioti da UFSCar/Araras pela amizade, co-orientação, participação efetiva no andamento dessa pesquisa e pelas oportunidades profissionais,

- À Escola Superior de Agricultura “Luiz de Queiroz” e ao Programa de Pós Graduação em Fisiologia e Bioquímica de Plantas pela formação profissional;

- Ao Centro de Ciências Agrárias - UFSCar/Araras pela abertura e por toda a estrutura e assistência necessárias à realização desse trabalho;

- A Prof ${ }^{a}$. Dra. Siu Mui Tsai e Prof. Dr. Otto J. Crocomo pelas preciosas sugestões durante a qualificação do trabalho;

- Ao Prof. Dr. Sizuo Matsuoka coordenador do PMGCA (Programa de Melhoramento Genético de Cana-de-Açúcar - UFSCar/Araras) pela atenção e apoio;

- Ao Prof Dr. Hideto Arizono da UFSCar/Araras pelas sugestões e fornecimento de preciosos contatos; 
- Ao Prof Dr. Yodiro Masuda da UFSCar/Araras pela amizade, simpatia e por estar sempre pronto à ajudar;

- A todos os diretores da CanaVialis S/A pela oportunidade profissional;

- Ao biólogo Guilherme Lagazzi por todos os momentos compartilhados, pelo amor e amizade, transformando-se em companheiro e colega de trabalho;

- Ao biólogo e amigo Ênio Tiago de Oliveira pela amizade e auxílios técnicos prestados durante todo o curso de mestrado;

- Aos Professores Dr. Ricardo Ferraz de Oliveira e Dr. Lázaro E. Pereira Peres pelos ensinamentos adquiridos e exemplo profissional;

- Ao amigo Guilherme Lacava de Moura pela amizade compartilhada de anos de trabalho em laboratório;

- Ao amigo pesquisador Carlos I. Vildoso pela preciosa amizade e apoio nestes últimos meses de trabalho;

- Ao amigo Roberto Gonçalves pela amizade e auxílios técnicos prestados no decorrer do trabalho;

- A Maria Solizete Granziol Silva, secretária do Programa de Pós-Graduação em Fisiologia e Bioquímica de Plantas pela amizade e estímulo;

- A todos os funcionários e colegas acadêmicos do Departamento de Fisiologia e Bioquímica de Plantas;

- As bibliotecárias Silvia e Eliana pelos serviços prestados;

- A todos que indiretamente contribuíram para a realização deste trabalho. 


\section{SUMÁRIO}

Página

RESUMO......

viii

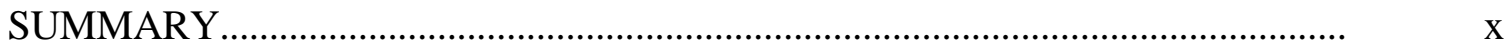

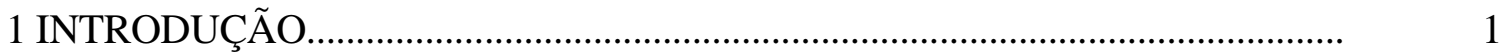

2 REVISAO DE LITERATURA..................................................................

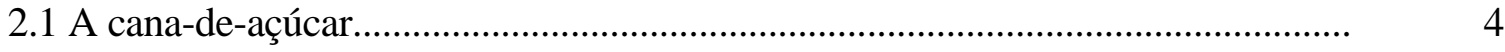

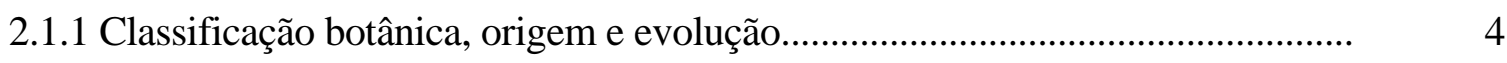

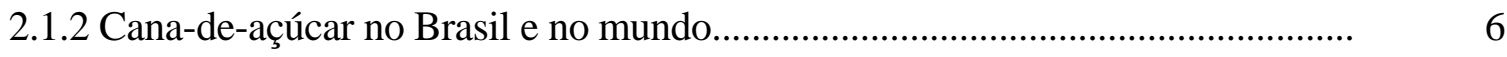

2.2 Historia, distribuição e importância do Raquitismo-da-soqueira RSD.................. 8

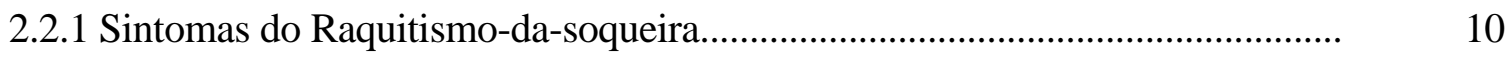

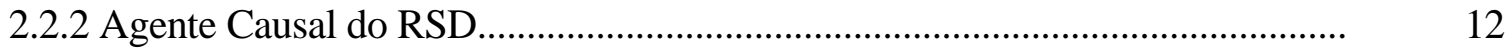

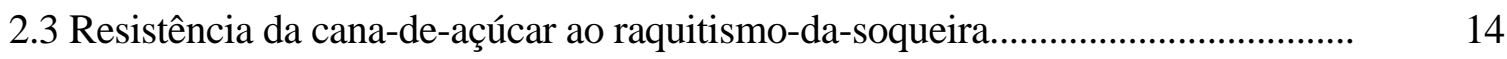

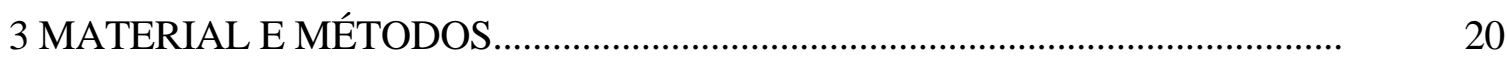

3.1 Material vegetal: seleção das variedades de cana-de-açúcar e obtenção de gemas 
3.2 Tratamento térmico para obtenção de plantas sadias............................................ 21

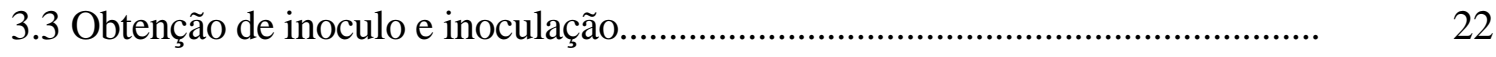

3.4 Brotação das gemas e transplantio das plântulas.....................................................

3.5 Manutenção das plântulas em casa-de-vegetação................................................. 25

3.6 Avaliação da taxa de colonização dos vasos do xilema por TBIA....................... 26

3.6.1 Amostragem....................................................................................... 26

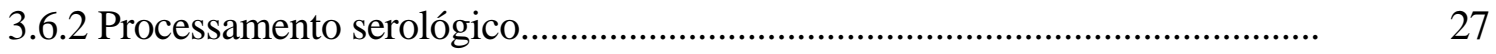

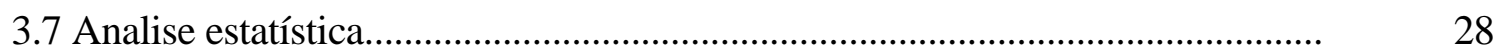

4 RESULTADOS E DISCUSSÃO.................................................................... 29

4.1 Discussão geral.........................................................................................

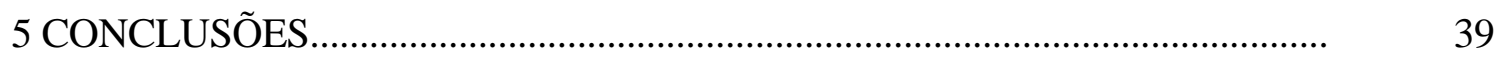

REFERÊNCIAS BIBLIOGRÁFICAS.................................................................. 42 


\section{AVALIAÇÃO DA RESISTÊNCIA DE VARIEDADES DE CANA-DE-AÇÚCAR AO RAQUITISMO-DA-SOQUEIRA COM BASE NA TAXA DE COLONIZAÇÃO DOS COLMOS POR Leifsonia xyli subsp.xyli}

Autora: PATRÍCIA BENITES ROS

Orientador: Prof. Dr. LUIZ ANTONIO GALLO

\section{RESUMO}

O método sorológico "tissue blot enzyme immunoassay" foi utilizado para determinar a taxa de colonização dos vasos do xilema por Leifsonia xyli subsp. xyli (Lxx) em colmos de 28 variedades de cana-de-açúcar, incluindo a CB47-355, CB41-76 e CB49-260 como padrão resistente, intermediário e suscetível, respectivamente. Para cada variedade, 16 gemas foram tratadas termicamente a $50,5^{\circ} \mathrm{C}$ por 2 horas e, em seguida, submetidas a banho fungicida a base de benomyl na dose de 6,5 g do princípio ativo por 10 litros de água. Oito gemas foram imersas por 10 minutos em caldo da CB49-260 sabidamente colonizada por Lxx diluído em água destilada na proporção 1:5 (“INOCULADO”) e a outra metade em água (“SADIO”). Após a inoculação, foram plantados três vasos (repetições) para o tratamento, sendo as plantas mantidas em casade-vegetação até a colheita durante 7 meses, quando então 2 colmos de cada vaso foram amostrados para determinar a taxa de colonização dos vasos. A variedade CB47-355 não 
apresentou nenhum vaso colonizado, enquanto na CB41-76 e CB49-260 a taxa de colonização foi igual a 17\% e 76\%, sendo classificadas como resistente, intermediária e suscetível, respectivamente, concordando com literatura prévia. Das variedades em teste, 12 comportaram-se como intermediárias e 13 como suscetíveis. No primeiro caso, a \%VC variou de 7 a 25 e, nas suscetíveis, de 25,7 a 76. Portanto, o aumento da taxa de colonização é praticamente linear da mais resistente para a mais suscetível, o que é característico de caráter quantitativo. Considerando que nenhuma variedade comercial mostrou-se resistente e que Lxx causa perdas significativas em todos os países produtores de cana-de-açúcar, sugere-se que os programas de melhoramento devem dirigir programas para a seleção de genitores e progênies para obter variedades resistentes. Enquanto isso não ocorre, atenção dever ser dada para o uso de mudas indexadas. 


\section{RESISTANCE OF BRAZILIAN SUGARCANE CULTIVARS TO RATOON STUNTING DISEASE BASEAD ON THE RATE OF STALK COLONIZATION BY Leifsonia xyli subsp. xyli}

Author: PATRÍCIA BENITES ROS

Adviser: Prof. Dr. LUIZ ANTONIO GALLO

\section{SUMMARY}

The tissue blot immunoassay (TBIA) for detecting Leifsonia xyli subsp. xyli (Lxx) colonized vascular bundles (CVB) were used in determining the reaction of 28 brazilian sugarcane cultivars to ratoon stunting disease (RSD), including CB47-355, CB41-76 e CB49-260 as resistant, intermediate and susceptible standards. For each cultivar, 16 buds were hot water treated at $50,5{ }^{\circ} \mathrm{C}$ for 2 hours and protected against root rots with benomyl. Eight buds of each cultivar were than inoculated with infected sap of the CB49-260 diluted 1:5 in water, and the remaining 8 buds were inoculated with distilled water for planting the control plots. The reps of each cultivar were planted in plastic plots at green house. At harvesting, seven months after planting, two stalks were sampled from each plot. The rate of colonization of vascular bandles by Lxx in stalks of 
each cultivar was determined. Statistical analysis by the univariate clustering method (Scott-Knott) was reliable for grouping genotypes according to their levels of Lxx resistance by the percentage of CVB. The cultivar CB47-355 did not present any CVB, while CB41-76 and CB49-260 presented 17\% and 76\%, being classified as resistant, intermediate and susceptible, in agreement with previous literature. Among the varieties in test, 12 were intermediates and 13 susceptibles. The percent of CVB among the intermediate and susceptible cultivars varied from $7 \%$ to $25 \%$ and 25,7 to $76 \%$, respectively. The knowledge of resistance of each cultivar is essential for advising the use of complementary phytossanitary measures to control the disease. Since all cultivars are intermediate or susceptible, the sugarcane breeding programs need specific works for selection and releasing of resistant cultivars. Before this, schemes of nurseries and the use clean seed cane are recommended. 


\section{INTRODUÇÃo}

A importância sócio-econômica da exploração da cultura canavieira em solos brasileiros é reconhecida desde os tempos do Brasil colônia. Atualmente, além dos aspectos sócio-econômicos, a cultura tem sua importância também reconhecida na área estratégica e ambiental, tendo o álcool como uma fonte renovável de energia menos poluente a qual já integra parte da matriz energética nacional e está sendo agora um dos produtos mais desejados pelo mercado internacional.

O cultivo da cana-de-açúcar está sujeita ao ataque de inúmeros patógenos, incluindo Leifsonia xyli subsp. xyli (Lxx), bactéria causal do raquitismo-da-soqueira (RSD), uma das doenças mais importantes e prevalente em todas as regiões canavieiras do mundo. A interação cana-de-açúcar X Lxx é bastante complexa, tal qual o efeito desta relação no crescimento da planta. Devido à ausência de sintomas específicos e facilmente visualizados, passados mais de 50 anos desde a descoberta, a doença é ainda endêmica nos canaviais do mundo (Ricaud C., 1974), causando perdas consideráveis (Hughes, 1974; Gillaspie, Jr. et al., 1989). As perdas decorrentes dessa doença podem ser superiores a 50\%, em cultivares suscetíveis e condições condutivas à interação hospedeiro-patógeno (Ricaud \& Ryan, 1989; Davis \& Bailey, 2000;). 
A exemplo de outros países, a canavicultura brasileira é alvo dos danos causados pelo RSD. Estimativa de queda de produtividade atingiu valores da ordem de 16\% a 37\% para os genótipos CB41-76, CB49-260 e IAC52-326 (Matsuoka, 1976; 1984). Os danos podem ter sido ainda maiores ao ser considerado que, por ocasião da década de 80, 90\% dos canaviais brasileiros estavam infectados por Lxx, em diferentes intensidades, e que os danos podiam chegar até 60\% (Sanguino, 1987). Na década de 90, o problema ainda persistia, pois muitas unidades produtoras desativaram o sistema de tratamento térmico para a produção de mudas sadias que era largamente utilizado na década de 80 (Ruas et al., 1987), alegando necessidade de redução de custos de produção. Além disso, os principais cultivares utilizados na época não apresentavam imunidade à bactéria (Chagas, 1996). Atualmente, somente no Estado de São Paulo, estima-se que o patógeno Lxx cause perdas anuais na casa dos 60 milhões de dólares (Giglioti, 1997).

O RSD é uma das doenças bacterianas mais difícil de ser controlada. Dificilmente se têm variedades resistentes e as medidas fitossanitárias para seu controle são ineficientes. A termoterapia não apresenta 100\% de eficiência na inativação de Lxx (Lopez-Rosa \& Adsuar, 1970; Matsuoka, 1971). Este fato, aliado à rápida expansão da cultura canavieira utilizando-se mudas sem as devidas qualidades fitossanitárias, proporcionou maior ocorrência de doenças em áreas tradicionais como também em áreas de expansão, comprometendo muitas vezes a produtividade agrícola causando preocupações quanto à ocorrência de surtos epidêmicos (Sordi, 1986). Por sua vez, a cultura de ápices meristemáticos por si só não limpa as mudas infectadas (Lee, 1988). 
A bactéria Lxx coevoluiu com a cana-de-açúcar, resultando numa estreita adaptação à colonização dos tecidos do xilema, num grau de parasitismo elevado e níveis baixos de patogenicidade, na maioria das variedades comerciais (Tokeshi, 1997a; 1997b). Desta forma, é difícil encontrar variedades imunes ao patógeno, podendo aquelas com alto nível de resistência horizontal serem portadoras sem sintomas. Obviamente, nestes casos, a densidade populacional da bactéria é menor que em cultivares suscetíveis, dificultando a diagnose (Davis et al., 1988a; 1988b). Porém, testes de rotina em programas de melhoramento genético da cana-de-açúcar para avaliar a resistência de variedades com base na taxa de colonização dos vasos do xilema por Lxx só começaram a ser introduzidos após o desenvolvimento da técnica "Tissue-blot enzyme immunoassay” (TBIA) (Harrison \& Davis, 1988). Esta técnica permitiu a avaliação da severidade do RSD com base na quantificação do número de feixes vasculares colonizados por Lxx em secções transversais de colmos de cana-de-açúcar. Assumindo que trata-se de uma técnica de baixo custo e passível de ser aplicada em grande número de amostras e que o número de vasos colonizados apresenta boa correlação com os danos na produção de cana-de-açúcar (Davis et al., 1994), o método tem sido adotado no mundo todo. Como no Brasil não existem relatos do uso desta técnica, o presente trabalho teve como objetivo introduzir a técnica aos nossos programas de melhoramento através da avaliação da resistência ao raquitismo-dasoqueira apresentada por variedades comerciais de cana-de-açúcar cultivadas na região centro-sul do Brasil, com base na taxa de colonização dos vasos do xilema por Leifsonia xyli subsp. xyli. 


\section{REVISÃO DE LITERATURA}

\subsection{A cana-de-açúcar}

\subsubsection{Classificação botânica, origem e evolução}

A cana-de-açúcar pertence à divisão Magnoliophyta, classe Liliopsida, subclasse Commilinidae, ordem Cyperales, família Poaceae, tribo Andropogonae e sub tribo Saccharininae (Castro et al., 2001).

A classificação botânica das espécies mais aceita é a de Jeswiet, desde 1925 (Castro et al., 2001). As espécies de cana de açúcar são classificadas da seguinte maneira (Castro et al., 2001; Matsuoka et al., 1999):

S. officinarum L. (2n=80): esta espécie é um complexo poliplóide, cujo centro de diversidade é a Nova Guiné, seu centro de origem é desconhecido. Admite-se que ela tenha surgido naquela mesma região, a partir de S. spontaneum, Miscanthus e Erianthus arundinaceus, passando por S. robustum. Constitui-se a espécie-base dos programas de melhoramento, para a qual faz-se a recorrência (nobilização), objetivando-se características especiais, como colmos suculentos com bom teor de sacarose, boa pureza do caldo e teor de fibra adequado para moagem. São exigentes em clima e solo e muito sensíveis a doenças, como o “mosaico”. Até 1925, no Brasil, principalmente no Estado 
de São Paulo, eram plantados os cultivares conhecidos como: Riscada, Roxa, Cristalina, Manteiga, Caiana, Preta entre outras, todas pertencentes a essa espécie.

S. spontaneum L. $(\mathbf{2 n}=\mathbf{4 0 - 1 2 8 ) : ~ e ́ ~ u m a ~ e s p e ́ c i e ~ a l t a m e n t e ~ p o l i m o ́ r f i c a , ~ q u e ~}$ cresce no trópico e subtrópico, provavelmente produto da introgressão entre membros do complexo Saccharum. É a espécie que, moderadamente, tem dado maior contribuição ao melhoramento, com suas características de vigor, dureza, perfilhamento e capacidade de rebrota de soqueira, especialmente devido ao vigoroso rizoma e a resistência aos estresses, doenças e pragas. São plantas de menor porte, colmos curtos e finos, fibrosos e praticamente sem açúcar, com sistema radicular bem desenvolvido e perfilhamento abundante, sendo menos exigentes, vegetando bem em condições adversas, são resistentes ao mosaico. Fazem parte desta espécie os cultivares Kans, da Índia e Glagah, de Java.

S. robustum Jesw (2n=60-205): supõem-se que esta espécie originou-se da introgressão de S. spontaneum com outros gêneros na Região de Nova Guiné. Admite-se que, a partir desta espécie, é que $S$. officinarum evoluiu, por meio de seleções humanas, a procura de tipos mais macios e ricos em caldo açucarado. Tem pouca participação nos híbridos atuais, exceto nos havaianos, as plantas apresentam porte alto, são muito fibrosas e muito pobres em sacarose, também são tolerantes à umidade e suscetíveis ao mosaico.

S. sinense $\operatorname{Roxb}(2 n=111-120)$ e $S$. barberi Jesw (2n=81-124): eram espécies cultivadas pelos nativos da China e do Norte da Índia, desde épocas pré-históricas, não havendo definição segura sobre a origem destas espécies. S. sinense provavelmente surgiu da introgressão de S. officinarum com Miscanthus, ou com S. spontaneum, na 
China após a introdução da primeira em épocas pré-históricas. Estas plantas apresentam colmos finos, fibrosos e regularmente ricos em sacarose, sistema radicular desenvolvido e menos exigentes em solos, suportando os secos e pobres, alguns cultivares são resistentes ao mosaico, outros não, dentre os cultivares dessa espécie destacam-se os conhecidos como cana de Ubá e Kavangire. Já S. barberi pode ter surgido de forma independente no noroeste da Índia, ou da introgressão de S. officinarum com Erianthus sect. Ripidium são plantas de porte médio a baixo, colmos finos, fibrosos e pobres em sacarose, consideradas rústicas e pouco exigentes em solo, susceptíveis ao mosaico e tolerantes ao frio, encontram-se dentro desta espécie as conhecidas como "Canas indianas”, destacando-se o Chunnee.

S. edule (2n=60-80): esta espécie é considerada atualmente um produto da introgressão de $S$. officinarum ou $S$. robustum com outro gênero, sendo uma série poliplóide, com formas aneuplóides. Alguns cultivares são restritos a nova Guiné e ilhas vizinhas, caracterizam-se pela produção de inflorescência intumescida com flores abortivas e que são utilizadas na alimentação humana.

\subsubsection{A cana-de-açúcar no Brasil e no mundo}

No mundo, a cana-de-açúcar é cultivada predominantemente em áreas subtropicais entre $15^{\circ}$ e $30^{\circ}$ de latitude, mas podendo se estender ate $35^{\circ}$ de latitude tanto norte quanto sul, sendo produzida comercialmente em mais de 70 países e territórios sendo os maiores produtores o Brasil, Cuba, Índia, México, China, Filipinas, Austrália, África do Sul, Estados Unidos da América, República Dominicana e Formosa. 
O Brasil é atualmente o maior produtor mundial, destacando-se os Estados de São Paulo, Rio de Janeiro, Minas Gerais, Pernambuco, Alagoas e Paraíba (Castro et al., 2001).

A trajetória da cana-de-açúcar para o Brasil iniciou-se na metade do século XVI, através de Martin Afonso de Souza que a trouxe para a Capitania de São Vicente (Castro et al., 2001). Os primeiros três séculos do cultivo de cana-de-açúcar no Brasil ficaram conhecidos como "ciclo da Creola”, devido ao predomínio desta variedade, sendo substituída mais tarde pela Caiana, mais rica e produtiva (Miocque \& Machado Jr, 1977).

Com o passar do tempo novas variedades foram sendo introduzidas como a Roxa, Salangor, Lousier e Kavangire, que tiveram seu cultivo encerrado devido a uma epidemia de Mosaico na década de 20. Este fato abriu espaço para a entrada de variedades japonesas (POJ) destacando-se POJ 36, POJ 213, POJ 2878 e POJ 2714 e mais tarde para variedades importadas de Coimbatore (Índia), Co281, Co290, Co331, Co413, Co419 e Co421. Mais uma vez a ocorrência de uma doença, desta vez o carvão, prejudicou as lavouras de cana-de-açúcar, e novos genótipos eram necessários (Matsuoka et al., 1999).

A partir de 1950 as variedades CB desenvolvidas na Estação Experimental de Campos (RJ), passaram a ser amplamente cultivada nos canaviais brasileiros, destacando-se a CB41-76 até o começo de1980, principalmente em São Paulo e, CB453, na mesma época, na região oeste de Minas Gerais, Rio de Janeiro, Espírito Santo e em todo Norte-Nordeste. Esta última perdura até hoje naqueles locais, sendo no Brasil, as variedades CB junto com a Co331, são as variedades de maior durabilidade deste século (Matsuoka et al., 1999). 
Em meados da década de 70 a agroindústria canavieira sofreu uma revolução com a chegada da variedade NA56-79, importada por Azzi e Paranhos. Na década de 80 já ocupava mais de 50\% da área cultivada com cana na época, superando a CB41-76, até então a mais cultivada, principalmente devido à sua produção, riqueza, precocidade e uma excelente brotação de soqueiras. Mais uma vez a ocorrência de uma doença, desta vez o carvão, associado aos danos causados pela ferrugem e o raquitismo da soqueira, causaram a condenação deste genótipo (Matsuoka, 1991; Matsuoka, 1999).

Após este período, os primeiros frutos obtidos pelos Programas de Melhoramento da Copersucar (variedades SP) e do IAA/Planalsucar (variedades RB), começavam a ser colhidos, personificados através de variedades como SP70-1143, SP71-1406 e RB72454 (Matsuoka et al., 1999).

\subsection{História, distribuição e importância do Raquitismo-da-soqueira (RSD)}

No verão de 1944 e 45 na Austrália, após uma primavera bastante seca, alguns canaviais do então novo e promissor cultivar Q 28 apresentavam soqueiras subdesenvolvidas. Embora nada tivesse sido observado em cana-planta, a mesma anomalia ocorria nas socas dos viveiros que deram origem a esses canaviais, sugerindo que já em 1942 a anomalia incidia sobre o viveiro da Q 28 e, a partir daí, tenha sido disseminado para canaviais comerciais (Steindl, 1961).

Em 1949, a natureza infecciosa do RSD foi comprovada, através de estudos de reprodução de sintomas a partir de inoculações artificiais com caldo extraído de colmos afetados (Steindl, 1949). Estes estudos determinaram também que o principal agente 
transmissor da doença era o próprio homem com suas ferramentas de trabalho (as máquinas de plantio, facões, etc) utilizados na colheita. Através da troca de germoplasmas contaminados, em virtude da ausência de sintomas característicos da doença, houve ampla disseminação do RSD para a maioria dos produtores de cana-deaçúcar do mundo (Gillaspie Jr. \& Teakle, 1989), inclusive para o Brasil (Veiga, 1956).

Inicialmente acreditava-se que o RSD fosse causado por um vírus, principalmente pelo fato de que não se conseguia cultivar o patógeno em cultura axênica, sendo filtrado e transmitido mecanicamente (Steindl, 1961). Isto estimulou a realização de estudos para caracterizar um possível vírus associado à doença (Gillaspie Jr. et al., 1973; Maramoroch et al., 1966; Matsuoka, 1972). No entanto, mais tarde, três diferentes grupos de pesquisadores, trabalhando independentemente, reportaram a descoberta de uma bactéria habitante do xilema como agente causal do RSD (Gillaspie Jr. et al., 1973; Maramoroch et al.1973; Teakle et al., 1973). Com base nestes resultados, Lui et al. (1974) e Tokeshi et al. (1974) tentaram identificar e classificar a bactéria do RSD como sendo a Xanthomonas vasculorum (causadora da gomose) e Xanthomonas albilineans (agente causal da escaldadura das folhas), respectivamente. Porém, somente nas décadas de 80 e 90, estudos modernos, permitiram conhecer um pouco mais sobre a doença (Gillaspie Jr. et al., 1989). Em meados da década de 80, o Dr. Michael J. Davis, na época trabalhando como bacteriologista no "Ft. Lauderdale Research and Education Center" da Universidade da Flórida, comandava uma equipe que foi capaz de isolar a bactéria em cultura axênica e confirmar sua patogenicidade através dos postulados de Koch (Davis et al., 1984). Classificaram-na como Leifsonia xyli subsp. xyli, ao mesmo 
tempo em que efetuaram uma reclassificação de todas as bactérias pertencentes ao gênero Corynebacterium.

A relação cana-de-açúcar X Leifsonia xyli subsp. xyli é bastante complexa, tal qual o efeito desta relação no crescimento da planta devido à ausência de sintomas, por esta razão, passados mais de 50 anos desde a descoberta desta doença, a qual ainda é endêmica nos canaviais do mundo causando perdas consideráveis, esta continua sendo alvo de intensa pesquisa (Ricaud et al., 1974; Hughes, 1974; Gillaspie, Jr. et al., 1989).

\subsubsection{Sintomas do Raquitismo-da-soqueira}

Como o próprio nome diz, colmos atrofiados e plantas de cana-de-açúcar subdesenvolvidas no campo consistem na forma de manifestação externa do RSD. Quando infectados, os cultivares suscetíveis têm seu crescimento retardado e, em condições extremas, apresentam um aspecto de murcha, necrose nas pontas e bordas das folhas e subseqüente morte de toda a touceira (Steindl, 1961). Como resultado do crescimento lento, a competição com plantas daninhas se agrava, acentuando os sintomas descritos acima (Gillaspie Jr. \& Davis, 1992).

Os sintomas externos do RSD podem ser tanto aumentados como mascarados pela disponibilidade de água para a planta, por isso, alguns cultivares, sob condições de umidade apropriada, podem suportar alta densidade populacional da bactéria, sem mostrar qualquer sintoma visível (Sivanesan \& Waller, 1986; Gillaspie Jr. \& Teakle, 1989; Gillaspie Jr. \& Davis, 1992). A presença e a intensidade dos sintomas causados pelo RSD são determinadas pelo genótipo e idade da cultura, além de condições climáticas. Quando presentes, os sintomas podem estar associados com outros fatores, 
como o ano agrícola com pluviosidade desfavorável e/ou práticas culturais inadequadas, que determinariam à planta uma condição de estresse (presença de plantas daninhas, compactação do solo, acúmulo ou falta de adubos, corretivos e herbicidas, ocorrência de outras doenças, etc.) (Steindl, 1961).

Uma das razões do demorado progresso no conhecimento desta interação é a dificuldade em diagnosticar a doença (Matsuoka, 1972; Ricaud, 1974). Quando da sua descoberta na Austrália, em meados da década de 40, levou-se cinco anos para efetivamente ser considerada uma doença transmissível (Steindl, 1950), e mais 25 anos para se descartar a hipótese de etiologia viral que se tornara senso comum (Steindl, 1961; Forbes et al., 1960; Gillaspie, Jr. et al., 1966; Gillaspie, Jr., 1970). Na década de 70 passou-se a discutir sua etiologia (Gillaspie, Jr. et al., 1974; Teakle, 1974), para ao final desta década se estabelecer definitivamente uma bactéria como seu agente causal (Davis et al., 1980) e se estabelecer sua identidade (Davis et al., 1984). Porém, ainda com dificuldade se evoluiu em métodos de detecção da presença bacteriana em plantas de cana-de-açúcar (Chagas \& Tokeshi, 1994; Iamauti \& Tokeshi, 1994; Croft et al., 1994; Davis et al., 1994).

A falta de sintomas externos característicos da doença sempre foi a maior dificuldade para se detectar a doença e seu agente causal. Na década de 70, Matsuoka (1972), procurando contribuir para minimizar essas dificuldades, avaliou diversas gramíneas que pudessem manifestar sintomas quando infectadas pelo agente causal do raquitismo-da-soqueira (RSD). Dentre algumas que efetivamente se infectaram, apenas algumas manifestaram sintomas e, assim mesmo, também na forma de descoloração vascular como a que ocorre na cana-de-açúcar. Porém pela grande redução no tempo de 
aparecimento, além da maior nitidez, o capim elefante (Pennisetum purputeum Schum.) se mostrou útil para auxiliar seu diagnóstico. Naquela época, entretanto, por se considerar a doença de etiologia viral, a inoculação das plantas foram feitas com caldo de cana que se pretendia diagnosticar, aventou-se então a possibilidade de erro devido à não especificidade dos sintomas (Betti et al., 1980).

Atualmente, com o desenvolvimento de métodos da biologia molecular de alta sensibilidade (Davis et al., 1988a; Fegan et al., 1998; Pan et al., 1998) e a possibilidade de se isolar a bactéria (Davis et al., 1980 e 1984) e, assim, se ter cultura bacteriana pura, tornou-se possível um estudo de validação dos antigos resultados de hospedeiras do RSD.

\subsubsection{Agente Causal da RSD}

Desde 1949, após a confirmação da natureza infecciosa do RSD (Steindl, 1949), a identificação e classificação de seu agente causal, percorreu um árduo e longo caminho, a dificuldade de isolamento do microrganismo, só pôde ser entendida 35 anos mais tarde, quando a natureza fastidiosa da bactéria associada ao RSD foi comprovada (Davis et al., 1984). Com esta publicação, os pesquisadores caracterizaram um novo gênero contendo algumas bactérias fitopatogênicas corineformes, incluindo Leifsonia xyli subsp. xyli, agente causal do RSD.

L. x. subsp. xyli é gram-positiva, corineforme, não móvel e aeróbica obrigatória. As células bacterianas são bastonetes pleomórficos de 0,25-0,5 $\mu$ m por 1-4 $\mu \mathrm{m}$, com forma reta ou levemente curva e ocasionalmente inchada na ponta ou no meio. 
As colônias apresentam aspecto não pigmentado e circular, com um diâmetro variando de 0,1 a 0,3 mm, quando crescidas em meio SC (Davis et al., 1984). A exemplo de outros membros do gênero Leifsonia, o patógeno do RSD não forma esporos e é caracterizado pela presença do ácido 2,4 diaminobutírico em sua parede celular, ausência de ácidos micolíticos e predominância de metaquinonas com 9 ou 10 cadeias de carbono (Davis et al., 1984; Davis, 1986; Young et al., 1992).

O conteúdo de G+C de L. $x$. subsp. xyli é 66 mol \%. O extrato de ácidos graxos totais possui de 17 a 24, 5 a 14 e 62 a 72\% dos ácidos 15:0 anteiso, 16:0 isso e 17:0 anteiso, respectivamente (Gillaspie Jr. \& Davis, 1992). Variação em patogenicidade e virulência entre strains de $L$. x. subsp. xyli não têm sido identificados, sendo os isolados de diferentes regiões do mundo muito similares quando comparados quanto à morfologia, serologia e bioquímica (Davis et al., 1980; Davis et al., 1984).

Para que uma planta de cana-de-açúcar seja infectada por Lxx é necessário que células do patógeno sejam mantidas ativas (sobrevivência) entre os diferentes ciclos da cultura (renovação do canavial, cana-planta e socas) em algum lugar (fonte de inoculo) e, posteriormente, sejam transportadas para dentro do tecido suscetível dos colmos (transmissão) (Giglioti, 1997).

Não existem relatos da sobrevivência de Lxx em sementes verdadeiras de canade-açúcar ou em insetos vetores, embora o solo possa atuar como fonte de inoculo (Autrey et al., 1991), na prática, a manutenção deste patógeno fica na dependência de plantas hospedeiras. Além da cana-de-açúcar, milho, sorgo e várias outras espécies de gramíneas comumente encontradas em canaviais podem suportar o crescimento da bactéria após inoculação (Gillaspie Jr. \& Teakle, 1989; Matsuoka, 1972). Em Cuba a 
doença foi transmitida para o sorgo, resultando em raquitismo (Wehlburg, 1956), na Lousiana, o híbrido sorghum-sudan grass mostrou murcha característica (Benda, 1975).

Embora muitas gramíneas tenham sido artificialmente inoculadas com a bactéria do RSD, nenhuma tem sido encontrada naturalmente infectada, dentro ou nas proximidades dos canaviais, descartando a hipótese de que hospedeiros alternativos naturais poderiam constituir uma estratégia de sobrevivência da bactéria. Contudo, este patógeno está sempre presente nesta cultura, pois a exploração econômica da cana-deaçúcar é caracterizada pela monocultura (continuidade espacial) e sobreposição de cultivos (continuidade seqüencial). Sendo assim, a bactéria sobrevive durante todo o ciclo da cultura colonizando sistematicamente os vasos do xilema e floema dos colmos de cana-de-açúcar, durante a entressafra, a sobrevivência é garantida pela presença de bactérias na coroa das soqueiras que permanecem no solo após o corte da cana.

\subsection{Resistência da cana-de-açúcar ao raquitismo-da-soqueira}

A interação do uso de variedades resistentes à produção de mudas sadias e, descontaminação de instrumentos de corte é sugerida porque o tratamento térmico de toletes não é $100 \%$ eficiente, persistindo um residual de bactérias ativas dentro dos colmos tratados (Gillaspie Jr. \& Teakle, 1989). A partir deste residual, devido à alta infectividade do caldo de colmos doentes, a doença apresentará uma rápida evolução para áreas vizinhas (evolução espacial), ou dentro do talhão, para as soqueiras subseqüentes (evolução temporal). Além disso, muitas vezes, essas medidas de controle não são devidamente conduzidas ou sequer utilizadas. Nestes casos, o uso de variedades 
com a capacidade de limitar a freqüência de infecções, a intensidade da colonização de seus tecidos por Lxx e as perdas decorrentes deste ataque consiste na única maneira de controlar eficientemente o RSD. Portanto, a maioria dos programas de melhoramento genético de cana-de-açúcar estão, se não envolvidos, pelo menos preocupados com a execução de atividades de rotina para a obtenção de variedades resistentes ou tolerantes ao RSD (Giglioti, 1997).Depois de Plavsic-Banjac \& Maramorosch (1972) terem observado bactérias nos vasos do xilema de colmos de cana-de-açúcar com sintomas de RSD, através de exames em microscópio eletrônico e eletromicrografia, vários trabalhos têm demonstrado ser a resistência de genótipos de cana-de-açúcar ao RSD devido à menor densidade populacional da bactéria em colmos infectados (Bailey, 1977; Davis et al., 1988a; Gillaspie Jr. et al., 1976; Koike et al., 1982).

Na tentativa de desenvolver um método de identificação de variedades resistentes com base na densidade populacional da bactéria do RSD, Gillaspie Jr. et al. (1973) estimaram a quantidade de células bacterianas em suco extraído de colmos das variedades CP44-101, CP65-367, L62-96, L65-69. A extração foi feita através da moagem dos colmos com seis meses de idade e a contagem de talos bacterianos no suco obtido com o auxílio de microscópio de contraste de fase. Esses autores sugeriram o uso desse método e concluíram que a parte basal (principalmente os nós) dos colmos continha mais bactéria, que as amostras poderiam ser conservadas em baixas temperaturas até duas semanas, e que a observação não necessitava ser imediatamente após a extração. O número de bactérias não foi igual nos diferentes variedades e entre as plantas do mesmo cultivar, sendo que canas apresentando sintomas conspícuos do RSD continham mais bactérias do que aqueles com sintomas indistintos. 
A utilidade do microscópio de contraste de fase foi demonstrada mais tarde por Bailey (1977) ao descrever a existência de uma relação direta entre severidade de reações das variedades afetadas pelo RSD e o número de bactérias observadas em preparação de tecidos de todas as partes das plantas. Entretanto, devido ao baixo número de bactérias observadas em tecidos da parte apical do colmo e em tecidos de colmos jovens, torna-se necessário o uso de secções de colmos maduros, para uma maior segurança na determinação da densidade populacional da bactéria do RSD.

$\mathrm{Na}$ tentativa de tornar o método aplicável em larga escala para avaliar resistência de clones ao RSD, Koike et al. (1982) avaliaram a possível correlação entre produção e contagem de bactérias em microscópio de contraste de fase, durante três anos. Verificaram então que a correlação ocorria para as variedades resistentes (que não sofreram perdas de produção e apresentaram pequeno número de bactérias) e para variedades suscetíveis (perda de produção e grande número de bactérias). Para variedades intermediárias os resultados não se mostraram consistentes, e os dados de produção sugeriram que dentro do grupo dos intermediários existem variedades resistentes e suscetíveis. A contagem se mostrou eficiente para identificar variedades extremamente resistentes ou suscetíveis, e, apesar desta limitação quanto à sensibilidade do método, os autores consideraram-na útil para identificação de variedades resistentes ao RSD.

A identificação e contagem das células da bactéria do RSD, pelo método do microscópio de contraste de fase seria muito trabalhosa em programas que manuseiam grande volume de variedades a cada ano (Giglioti, 1997). Por esse motivo, após o isolamento e classificação da bactéria do RSD, foi desenvolvida a técnica de contagem 
direta de anticorpo fluorescente (fluorescent-antibody-direct-count $=$ FADC) em filtros (Davis, 1985). A reação específica do antissoro com Lxx possibilita a contagem de células bacterianas que ficam fluorescentes (avermelhadas) sob o microscópio de epifluorescëncia. Desta forma, a técnica detecta pelo menos $10^{4}$ células $/ \mathrm{ml}$, sendo 10 vezes mais sensitiva que o microscópio de contraste de fase.

FADC foi utilizada para estudar a distribuição e variabilidade quantitativa de populações de Lxx em colmos de variedades de cana-de-açúcar diferindo quanto à resistência ao RSD (Davis et al., 1988ab). Tanto a velocidade de crescimento como a quantidade máxima da população do patógeno, atingiram valores mais elevados nos suscetíveis, quando um total de nove variedades foram amostradas em três épocas sucessivas. Internódios maduros apresentam maior densidade populacional em relação aos mais jovens, sugerindo a necessidade de se testar variedades em fases mais adiantadas do ciclo de crescimento da planta. À medida que os tecidos ficavam maduros, melhor correlação entre densidade populacional de Lxx e danos de produção era observada. Estas informações animaram o Dr. Davis na sua busca por um método eficaz para identificar genótipos resistentes ao RSD. Em 1988, sob sua orientação, o Dr. Harrison conclui seus trabalhos de Pós-doutoramento apresentando a técnica que hoje é de grande utilidade em programas de melhoramento de cana-de-açúcar para quantificar a colonização de tecidos vasculares por Lxx: “Tissue-blot enzyme immunoassay”- TBIA (Harrison \& Davis, 1988).

O processo TBIA é constituído por diversas etapas. Primeiramente, cilindros de tecido da região central dos entrenós de colmos de cana-de-açúcar são amostrados. Este tecido é centrifugado de maneira a coletar o suco de cada feixe vascular em membrana 
de nitrocelulose. Após o processamento serológico, feixes vasculares colonizados por Lxx são identificados na membrana pela coloração azulada, quando observados através de microscópio estereoscópio. Depósitos coloridos de dimensões similares à de um metaxilema individualizado podem ser observados em membranas processadas.

Com o TBIA foi demonstrado que a resistência de variedades de cana-deaçúcar estava associada com uma redução na colonização dos tecidos vasculares do colmo por Lxx (Harrison \& Davis, 1988). Nesse mesmo trabalho, os autores obtiveram excelente correlação $(\mathrm{R}=0,97)$ entre o número de vasos colonizados $(\mathrm{VC})$ e a densidade populacional do patógeno determinada pela técnica FADC. Além disso, comparações de dados históricos de danos na produção de cana por parcela com VC indicaram certa similaridade no nível de resistência obtido pelos dois parâmetros, o que foi demonstrado mais tarde por Davis et al. (1984). Este fato, aliado à sensibilidade, praticidade e capacidade de processar amostras múltiplas, fez com que o TBIA fosse adotado pelo programa de melhoramento genético da cana-de-açúcar do Estado da Flórida (Comstock et al., 1996a) para estimar incidência (\% de colmos infectados) e a severidade (número médio de feixes vasculares colonizados) do RSD, visando a identificação e seleção de variedades resistentes.

Nas estações de melhoramento de Canal Point (FL) e Houma (LO) a técnica tem sido utilizada com sucesso (Comstock et al., 1996a). Porém, Grisham \& Comstock (informações pessoais) têm alertado para a possibilidade da não correlação absoluta entre VC e danos de produtividade pelo RSD, tendo como exemplo o genótipo CP79318 cujo elevado número de VC não tem repercutido em danos significativos. A existência de genótipos tolerantes levanta a hipótese de que os vasos podem, por vezes, 
permanecerem funcionais sem comprometer o transporte de água e sais minerais. Esse fato foi comprovado por Giglioti (1997). Este autor obteve baixa correlação $(r=0,40)$ entre a média do número de VC e vasos não funcionais (VNF) quando 19 genótipos diferindo quanto ao grau de resistência ao RSD foram avaliados. 


\section{MATERIAL E MÉTODOS}

\subsection{Material vegetal: seleção das variedades de cana-de-açúcar e obtenção de gemas}

Na Tabela 01 observa-se a relação de vinte e oito variedades ou clones promissores e os três padrões com níveis diferenciais de resistência a Leifsonia xyli subsp. xyli que foram avaliados pelo presente estudo. A escolha das variedades em teste baseou-se na ocupação da área cultivada, no potencial comercial ou como progenitores de futuros cruzamentos e na disponibilidade de mudas para a instalação do experimento.

As variedades CB47-355, CB41-76 e CB49-260 foram incluídas como padrões resistentes, intermediário e suscetível, respectivamente. A escolha dos padrões baseou-se nos resultados obtidos por Matsuoka (1980), Douglas (1981) e Valarini \& Tokeshi (1981).

As gemas foram obtidas a partir da coleção de germoplasma do Centro de Ciências Agrárias da Universidade Federal de São Carlos. Para cada variedade, foram extraídas e selecionadas 16 gemas, as quais foram submetidas ao tratamento térmico (TT). 
Tabela 1. Relação das Variedades Selecionadas

\begin{tabular}{|c|c|c|c|}
\hline Número & Variedades & Número & Variedades \\
\hline 1 & CB47-355 & 15 & RB855113 \\
\hline 2 & SP81-3250 & 16 & SP79-1011 \\
\hline 3 & RB865513 & 17 & SP86-155 \\
\hline 4 & RB928064 & 18 & SP79-2233 \\
\hline 5 & RB825336 & 19 & RB845210 \\
\hline 6 & RB855002 & 20 & RB855046 \\
\hline 7 & RB925268 & 21 & RB935621 \\
\hline 8 & SP80-1842 & 22 & RB935925 \\
\hline 9 & SP80-1816 & 23 & SP87-365 \\
\hline 10 & SP80-3280 & 24 & RB785148 \\
\hline 11 & CB41-76 & 25 & RB806043 \\
\hline 12 & RB867515 & 26 & SP70-1143 \\
\hline 13 & RB835054 & 27 & RB855595 \\
\hline 14 & SP83-2847 & 28 & CB49-260 \\
\hline
\end{tabular}

\subsection{Tratamento Térmico para obtenção de plantas sadias}

As 16 gemas selecionadas para cada variedade foram submetidas ao processo de tratamento térmico, numa tentativa de inativar as células de Leifsonia xyli subsp. xyli. Como vários trabalhos citam que o tratamento térmico normalmente feito com os 
tanques comerciais não apresenta 100\% de eficiência (Lopez-Rosa \& Adsuar, 1970; Matsuoka, 1984; Sanguino, 1989; Gheller, 1986), utilizou-se um equipamento pequeno tipo banho-maria, com capacidade para 21 litros de água, com circulação e com melhor controle digital de temperatura, modelo 500/4DE do fabricante Nova Ética S.A. Inicialmente, as gemas de cada variedade foram acondicionadas em saquinhos de nylon (tipo saco de batata), os quais foram então tratadas com água quente a $50,5^{\circ} \mathrm{C}$ por duas horas no banho-maria. Adicionalmente ao controle digital de temperatura, um termômetro permaneceu durante todo o período de tratamento com o bulbo sensor submerso na água e, a cada 10 minutos, a temperatura foi aferida para garantir maior eficiência no controle de possíveis infecções nas gemas que vieram da coleção de germoplasma. Após resfriamento das gemas isoladas, os saquinhos foram mergulhados numa suspensão fungicida a base de benomyl (Benlate 500) na dose de 6,5 g do princípio ativo por 10 litros de água, visando o controle de fungos durante a brotação das gemas, principalmente Ceratocystis paradoxa (podridão abacaxi).

\subsection{Obtenção de inoculo e inoculação}

Para representar as plantas do tratamento CONTROLE, metade das gemas tratadas termicamente foi inoculada com água estéril. O restante, para compor o tratamento INOCULADO, foi inoculado com caldo de cana sabidamente infectada. O inoculo foi obtido de plantas da variedade CB49-260 com 10 meses de idade da coleção de germoplasma do Centro de Ciências Agrárias da Universidade Federal de São Carlos. Foram coletados colmos que se apresentavam subdesenvolvidos com sintomas de vírgulas na região dos nós observados quando se cortou o colmo longitudinalmente. De 
cada colmo da fonte de inoculo foi retirada uma amostra a qual foi submetida ao método TBIA para comprovar a presença de Leifonia xyli subsp. xyli na fonte de inoculo. O caldo destes colmos foi extraído, sendo este, por sua vez, diluído em água destilada na proporção 1:5. No total, foram obtidos 25 litros de inóculo, incluindo gelo para evitar sua fermentação, uma vez que o caldo é rico em açúcar. Cada saco de nylon (tipo saco de batata) contendo as gemas previamente tratadas termicamente foi submerso, um a um, em um balde contendo o inóculo, durante 10 minutos.

\subsection{Brotação das gemas e transplantio das plântulas}

Após a inoculação, as gemas foram imediatamente plantadas em caixas plásticas com dimensões de 46,7 x 30,2 x 11 cm (largura x comprimento x altura) contento 14 litros de areia lavada como substrato (Figura 1). Trinta e quatro dias após o plantio das gemas, as plântulas obtidas foram transplantadas para vasos de 20 litros (Figura 2) contendo substrato à base de solo de barranco, areia grossa e composto orgânico “Compomax” (Cia Fértil, Araras/SP) na proporção de 3:1:1. O conteúdo de macro e micronutrientes desse substrato estão apresentados nas Tabelas 2 e 3. De cada variedade, foram plantados três vasos (repetições), tanto para o tratamento CONTROLE como para o INOCULADO. 
Tabela 2. Análise química dos macronutrientes do solo dos vasos experimental conduzido em casa de vegetação

\begin{tabular}{|c|c|c|c|c|c|c|c|c|c|c|c|}
\hline & $P$ Resina & $\mathrm{MO}$ & $\mathrm{pH}$ & $\mathrm{K}$ & $\mathrm{Ca}$ & Mg & $\mathrm{H}+\mathrm{Al}$ & Al & SB & CTC & $\mathbf{V}$ \\
\hline VASO & $\mathrm{mg} / \mathrm{dm}^{3}$ & g/dm & $\mathrm{Ca} \mathrm{Cl} 2$ & \multicolumn{7}{|c|}{$\mathrm{mmol}_{\mathrm{c}} / \mathrm{dm}^{3}$} & $\%$ \\
\hline $\begin{array}{c}20 \\
\text { Litros }\end{array}$ & 465 & 30 & 6,3 & 9,9 & 90 & 17 & 12 & 0,4 & 116,9 & 128,9 & 91 \\
\hline
\end{tabular}

Tabela 3. Análise química dos micronutrientes do solo dos vasos experimental conduzido em casa de vegetação

\begin{tabular}{ccccccc}
\hline & B & Cu & Fe & Mn & Zn & S \\
\hline VASO & & & \multicolumn{5}{c}{$\mathbf{m g} / \mathbf{d m}^{\mathbf{3}}$} & & \\
20 Litros & 1,13 & 2,8 & 63 & 10,6 & 3,1 & 450 \\
\hline
\end{tabular}

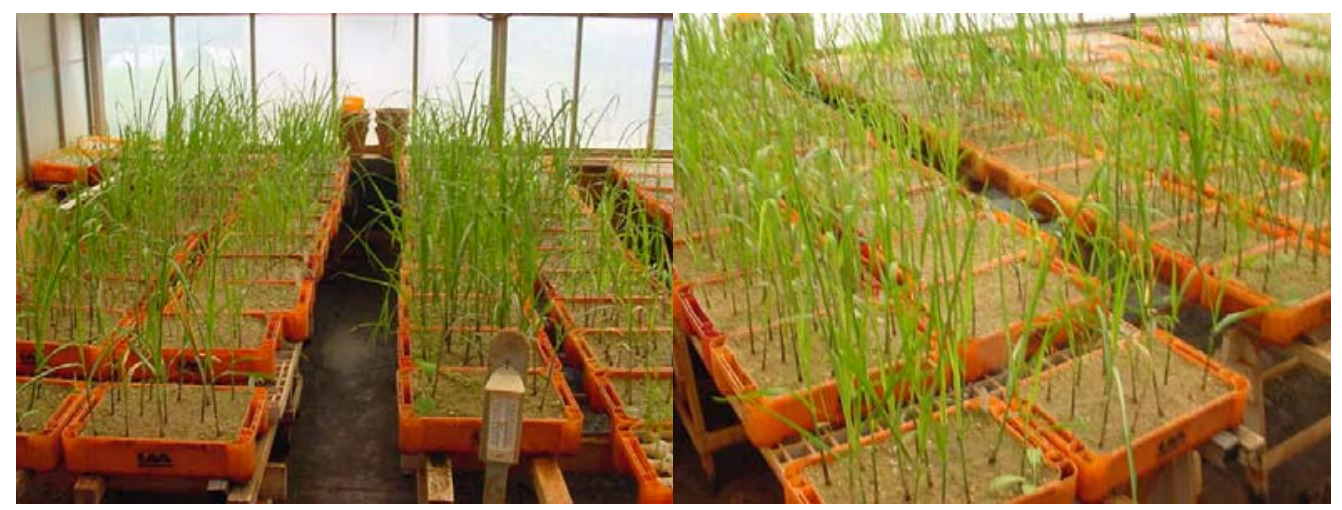

Figura 1- Germinação em caixas plásticas contendo areia 


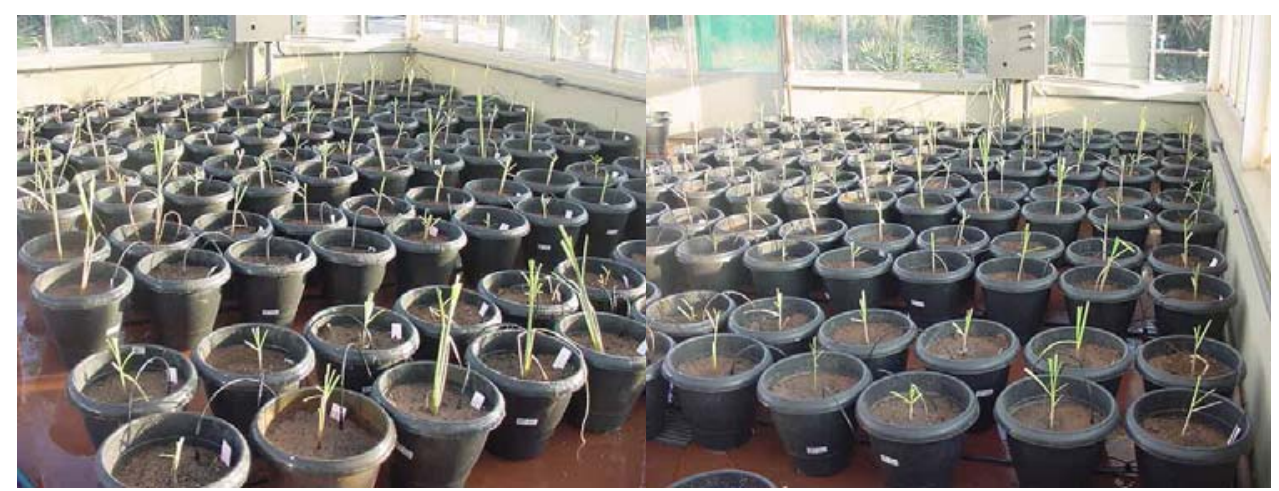

Figura 2 - Ensaio de resistência e tolerância de cultivares de cana de açúcar ao RSD logo após o transplante

\subsection{Manutenção das plântulas em casa-de-vegetação}

Após o transplantio, os vasos foram transferidos para uma casa-de-vegetação com sistema de resfriamento por nebulização acionada quando a temperatura atingia valores superiores a $30^{\circ} \mathrm{C}$. O sistema possuía um controlador digital de temperatura e umidade modelo EVERY CONTROL / EC 3-180. A irrigação dos vasos foi feita duas vezes ao dia, durante todo o desenvolvimento das plantas, por sistema de gotejamento com controlador modelo GALCON AC4-8004.

Para manutenção das plantas, 14 adubações foram feitas ao longo dos sete meses que as plantas permaneceram nesse ambiente até serem amostradas para determinar a taxa de colonização dos vasos do colmo por Leifsonia xyli subsp. xyli. 


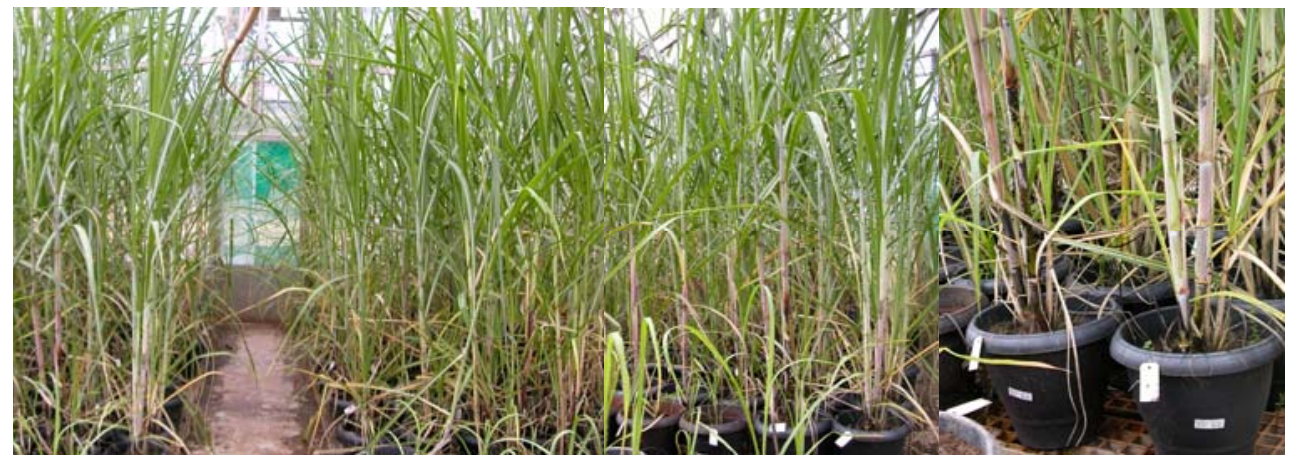

Figura 3 - Experimento, cinco meses após o transplantio

\subsection{Avaliação da taxa colonização dos vasos do xilema por TBIA}

Para identificar os vasos colonizados por Leifsonia xyli subsp. xyli, foi utilizado o método "Tissue-blot enzyme immunoassay" (TBIA) desenvolvido por Harrison \& Davis (1988) e modificado por Giglioti (1997).

\subsubsection{Amostragem}

De cada parcela (vaso) foi colhido o colmo primário de cana-de-açúcar com oito meses e meio de idade. Para tanto, os colmos foram inicialmente limpos (despalhados) e cortados próximo ao nível do solo. Do segundo internódio basal, foi retirada uma secção transversal de $10 \mathrm{~mm}$ de diâmetro e $10 \mathrm{~mm}$ de altura (cilindro). Posteriormente, os cilindros foram acondicionados dentro de poços individuais em placas plásticas, com uma das superfícies do corte transversal do colmo sobre uma membrana de nitrocelulose (Bio-Rad, $30 \mathrm{~cm}$ x $3.5 \mathrm{~m}, 0,45 \mu \mathrm{m}$ ). A membrana tinha sido colocada sobre camada de papel Whatman de três milímetros de espessura com uma 
subcamada de papel toalha absorvente e suporte plástico no fundo. As placas foram então centrifugadas a 1.700 g por 15 minutos para forçar a saída da seiva do xilema, formando um "pellet" de bactérias sobre a membrana de nitrocelulose diretamente abaixo dos feixes vasculares colonizados pela bactéria do RSD. Subseqüentemente, os cilindros foram transferidos para outra placa e as membranas foram secas em estufa por uma hora a $80^{\circ} \mathrm{C}$ e estocadas, por no máximo uma semana, até serem submetidas a um procedimento serológico. No dia seguinte, já secos, os cilindros foram observados em um estereomicroscópio para se contar o número total de vasos.

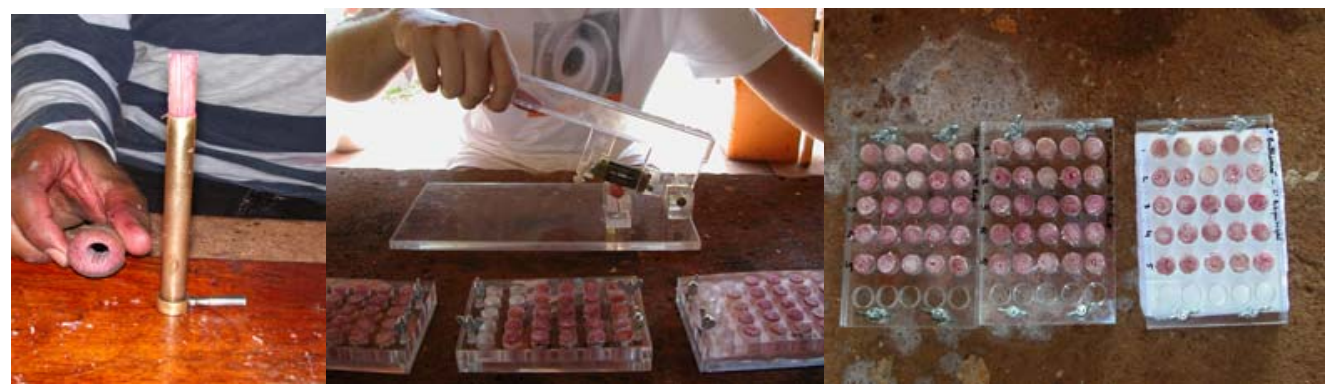

Figura 4 - Obtenção dos cilindros e acondicionamento em placas para obtenção do pellet de bactérias

\subsubsection{Processamento serológico}

Para detectar os tecidos vasculares colonizados por Lxx, foi utilizado o processo desenvolvido por Harrison \& Davis (1988) e modificado por Davis et al. (1994). Todo o procedimento foi conduzido em agitador rotatório a 60 rpm. Inicialmente, as membranas foram bloqueadas durante 30 minutos em tampão Tris (100mM Tris-HCl, 150 mM NaCl, pH 7,5) mais leite em pó desnatado na proporção de 2\% (p/v) e lavadas em tampão Tris por 1 minuto, sendo incubadas por uma hora em 
antissoro contra o strain F-1 de Leifsonia xyli subsp. xyli fornecido pelo Dr. M.J. Davis (“Department of Plant Pathology, University of Florida, Homestead”) diluído na proporção de 1:8000 em tampão Tris e lavadas três vezes, com o mesmo tampão, durante cinco minutos cada. Após a lavagem, as membranas foram novamente incubadas por uma hora em antissoro de cabra contra IgG de coelho conjugado com fosfatase alcalina (Sigma Chemical Co.) diluído 1:1.000 em tampão Tris e lavadas duas vezes no mesmo tampão. Em seguida, as membranas foram incubadas em solução substrato ("naphtol AS phosphate, N,N-dimethylformamide, Tris, Fast Blue Salt e cloreto de magnésio”) por 20 a 30 minutos, quando as manchas azuis escuras apareceram nas membranas, onde L.x. subsp. xyli de feixes vasculares infectados foi depositado. O número de vasos colonizados (VC) foi identificado e contado nas membranas, com auxílio de um estereomicroscópio, permitindo a quantificação da severidade da colonização através do parâmetro porcentagem de vasos colonizados (\%VC).

\subsection{Análise Estatística}

Após transformação dos dados pela fórmula y = sqrt $(\% \mathrm{VC}+0,5)$, as médias (y) foram agrupadas pelo método de análise de agrupamento univariado proposto por Scott-Knott (1974). Este método, de acordo com Giglioti (1997), quando comparado com o teste de comparação múltipla (Duncan, 1955), apresenta a vantagem de classificar genótipos em grupos discretos, ou seja, sem sobreposição, o que é sempre desejado pelos fitopatologistas e/ou melhoristas, pois elimina qualquer efeito subjetivo, no momento da separação dos grupos. 


\section{RESULTADOS E DISCUSSÃO}

O número de vasos amostrados e a taxa de colonização dos vasos por Leifsonia xyli subsp. xyli (\%VC) de cada variedade avaliada estão apresentados na Tabela 4. Em todas as parcelas do tratamento CONTROLE, nenhum vaso colonizado foi observado, indicando que o processo adotado para a inativação de células de Lxx possivelmente presentes nos colmos das variedades avaliadas foi eficiente. Portanto, as taxas de colonização observadas no tratamento INOCULADO decorreram exclusivamente a partir de células de Leifsonia xyli subsp. xyli (Lxx) presentes no inoculo preparado, indicando mais uma vez alta taxa de infecção do caldo, mesmo quando diluído na proporção 1:5 em água. A figura 5 mostra os vasos colonizados nas amostras de colmos de CB49-260 utilizada como fonte de inoculo.

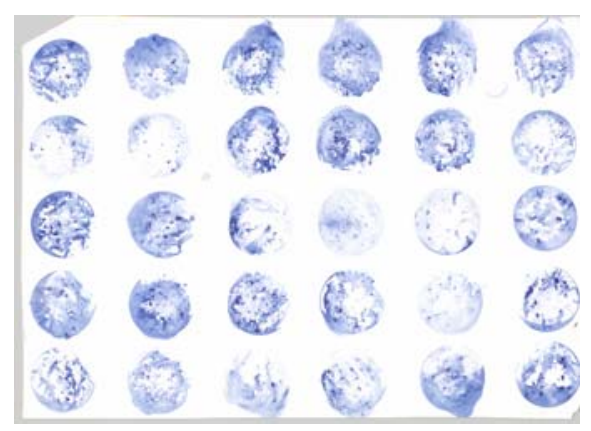

Figura 5 - Colmos de CB49-260 utilizados como fonte de inoculo. Diagnose positiva para raquitismo-da-soqueira (Leifsonia xyli subps. xyli). 
As análises de variância para \%VC evidenciaram diferenças significativas entre variedades, sendo possível agrupá-las quanto ao nível de resistência a Lxx (Tabela 4), através da separação de médias pelo método de análise de agrupamento (Scott \& Knott, 1974). A variedade CB47-351 não apresentou nenhum vaso colonizado, enquanto na CB4176 e CB49-260 a taxa de colonização foi igual a 17\% e 76\%, sendo classificadas como resistente, intermediária e suscetível, respectivamente. Portanto, os resultados do presente estudo corroboram os níveis de resistência pré-estabelecidos para essas variedades (Matsuoka, 1980; Valarini \& Tokeshi, 1981; Douglas, 1981), sendo interessante a inclusão dos mesmos com padrões em testes de resistência varietal. Variedades cujas taxas de colonização por Lxx não diferem estatisticamente daquela apresentada pela CB47-355 devem ser consideradas como resistentes. As que não diferem da CB41-76 e CB49-260 devem ser consideradas como intermediárias e suscetíveis, respectivamente.

As análises de variância para \%VC evidenciaram diferenças significativas entre as variedades, sendo perfeitamente possível agrupá-las quanto ao nível de resistência a Lxx, através da separação das médias pelo método de análise de agrupamento de Scott \& Knott (1974). As \%VC das variedades SP81-3250, RB865513, RB928064, RB825336, RB855002, RB925268, SP80-1842, SP80-1816, SP80-3280, RB867515, RB835054, SP83-2847 e RB855113 não diferiram significativamente daquele apresentado pela CB41-76, portanto, classificando estas variedades como intermediárias. Por outro lado, as \%VC das variedades SP79-2233, RB845210, RB855046, RB935621, RB935925, SP87-365, RB785148, RB806043, SP70-1143 e 
RB855595 não diferiram daquele apresentado pela CB49-260, classificando estas variedades como suscetíveis. Nas variedades intermediárias, a \%VC variou de 7 a 25 e, nas suscetíveis, de 25,7 a 76 (Figura 7).

Tabela 4. Porcentagem de vasos colonizados por Leifsonia xyli subsp. xyli e respectivo nível resistência de 28 variedades de cana-de-açúcar

\begin{tabular}{|c|c|c|}
\hline Variedade & \% Vasos Colonizados* & Nível de Resistência \\
\hline CB47-355 & $0,71 \mathrm{a}$ & Resistente \\
\hline SP81-3250 & $2,74 b$ & Intermediário \\
\hline RB865513 & $3,15 b$ & Intermediário \\
\hline RB928064 & $3,53 b$ & Intermediário \\
\hline RB825336 & $3,66 b$ & Intermediário \\
\hline RB855002 & $3,66 b$ & Intermediário \\
\hline RB925268 & $3,85 b$ & Intermediário \\
\hline SP80-1842 & $3,96 b$ & Intermediário \\
\hline SP80-1816 & $3,98 b$ & Intermediário \\
\hline SP80-3280 & $3,98 b$ & Intermediário \\
\hline CB41-76 & $4,1 b$ & Intermediário \\
\hline RB867515 & $4,75 b$ & Intermediário \\
\hline RB835054 & $4,76 b$ & Intermediário \\
\hline SP83-2847 & $4,86 b$ & Intermediário \\
\hline
\end{tabular}


Tabela 4. Porcentagem de vasos colonizados por Leifsonia xyli subsp. xyli e respectivo nível resistência de 28 variedades de cana-de-açúcar

\begin{tabular}{|c|c|c|}
\hline Variedade & \% Vasos Colonizados* & Nível de Resistência \\
\hline RB855113 & 5,05b & Intermediário \\
\hline SP79-1011 & $5,44 c$ & Suscetível \\
\hline SP86-155 & $5,7 c$ & Suscetível \\
\hline SP79-2233 & $6,13 c$ & Suscetível \\
\hline RB845210 & $6,15 c$ & Suscetível \\
\hline RB855046 & $6,22 \mathrm{c}$ & Suscetível \\
\hline RB935621 & $6,36 c$ & Suscetível \\
\hline RB935925 & $6,59 c$ & Suscetível \\
\hline SP87-365 & $6,96 \mathrm{c}$ & Suscetível \\
\hline RB785148 & $6,97 c$ & Suscetível \\
\hline RB806043 & 7,31c & Suscetível \\
\hline SP70-1143 & $7,38 \mathrm{c}$ & Suscetível \\
\hline RB855595 & $7,58 \mathrm{c}$ & Suscetível \\
\hline CB49-260 & $8,69 c$ & Suscetível \\
\hline
\end{tabular}




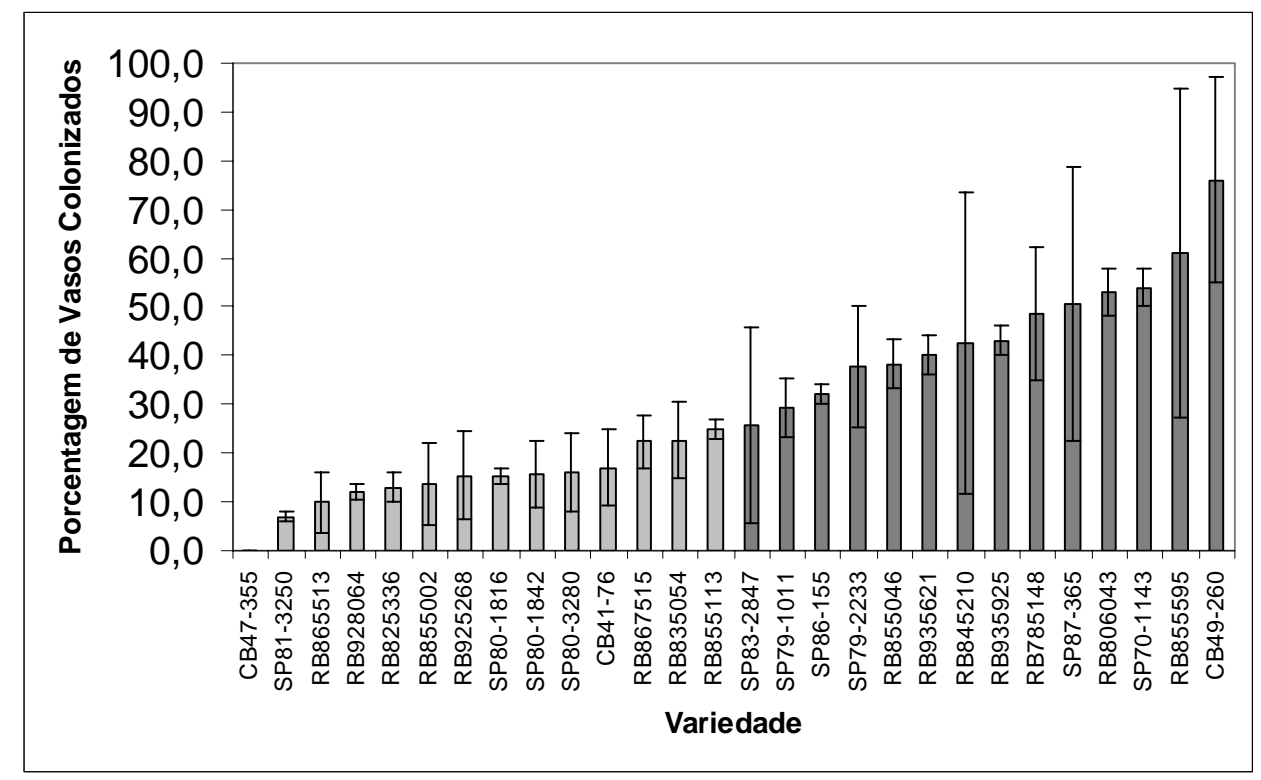

Figura 6 - Taxa de colonização dos vasos do xilema por Leifsonia xyli subsp. xyli de colmos de 28 variedades de cana-de-açúcar e os respectivos intervalos de confiança

Pelo método de análise de agrupamento de Scott \& Knott (1974) a colocação de cada variedade no grupo das resistentes, intermediárias e suscetíveis foi relativa à posição de cada variedade, sendo a resistência a Lxx foi determinada quantitativamente como um caráter típico da resistência horizontal (Vanderplank, 1984). Este tipo de análise é muito interessante, pois a cana-de-açúcar, por ser uma planta polifilética e de propagação vegetativa, desenvolveu naturalmente, ao longo de sua evolução, a resistência horizontal para a maioria de suas doenças (Matsuoka, 1993; Tokeshi, 1983). A resistência durável é de capital importância estratégica para a segurança de uma cultura monoclonal, extensiva e com sobreposição de cultivos (Robinson, 1987), como é praticada a agricultura canavieira.A vantagem do método de agrupamento de Scott- 
Knott para classificação de variedades quanto ao grau de resistência a Lxx, de acordo com Giglioti (1997), é que ele classifica as variedades em grupos discretos, ou seja, sem sobreposição, o que é sempre desejado pelos fitopatologistas e/ou melhoristas, pois, quando relacionado com a reação de padrões resistentes, intermediários e suscetíveis, elimina qualquer efeito subjetivo, no momento da separação dos grupos.

A resistência de variedades de cana-de-açúcar a Lxx está associada com baixa taxa de colonização de colmos, confirmando resultados prévios (Harrison \& Davis, 1988; Davis et al., 1994; Miller et al., 1995; Giglioti, 1997). É interessante observar que a intensidade de colonização, medida pelo número de vasos colonizados no terceiro internódio basal de 10 variedades, foi correlacionada positivamente $(\mathrm{r}=0,95)$ com a densidade populacional da bactéria em extratos vasculares destes tecidos (Harrison \& Davis, 1988). Além disso, a resistência à colonização foi também relacionada $(r=0,93)$ com a disseminação do RSD no campo, quando seis variedades foram estudas(Comstock et al., 1996b). Tanto a densidade populacional (Gillaspie et al., 1976; Koike et al., 1982; Davis et al., 1988b;) como a disseminação do RSD no campo (Damann, 1992) apresentaram correlação direta com a suscetibilidade ao RSD. Baseados nesses resultados, na alta herdabilidade da resistência da cana-de-açúcar ao RSD (Miller et al., 1995) e na significativa correlação $(r=0,51$ a 0,84$)$ entre o número de VC e danos na produção (Davis et al., 1994), a intensidade da colonização medida pelo número de VC está sendo utilizada com sucesso como parâmetro para selecionar variedades resistentes ao RSD no Estado da Flórida (Comstock et al., 1996a). Portanto, a avaliação da resistência de variedades de cana-de-açúcar com base na da taxa de colonização dos vasos do xilema por Lxx, através do parâmetro \%VC, tem grandes implicações com a 
epidemiologia do RSD. As variedades avaliadas no presente estudo devem agora ser submetidas a ensaios para avaliar o efeito da colonização dos vasos do xilema na produção de colmos e açúcar.

Embora as bases responsáveis para a diferença de colonização das variedades por Lxx não tenham sido objetivo do presente estudo, pode-se supor que características intrínsecas da anatomia vascular na região nodal dos colmos podem estar envolvidas de maneira a restringir a distribuição do patógeno ao longo do xilema (Teakle et al., 1975a; 1978). Teakle et al. (1975a) demonstraram que, de 11 variedades examinadas, o número de feixes vasculares enegrecidos, após a passagem de corante da Índia (carvão coloidal) através da região nodal de colmos sadios de cana-de-açúcar, foi negativamente correlacionado com a resistência ao RSD. Similarmente, a taxa de movimento de água através da região nodal de colmos sadios também apresentou correlação negativa com a resistência ao RSD (Teakle et al., 1975b; 1978). Tanto a redução no fluxo de água como a limitação na passagem de partículas do corante dentro do xilema, foram atribuídas a uma maior ramificação dos vasos do metaxilema na região nodal, resultando em menos vasos que passaram diretamente através dos nós, ou seja, em genótipos resistentes (Teakle et al., 1978). A formação de géis é também considerada um mecanismo de defesa da planta para localizar o patógeno no sistema vascular, sendo esta substância originada, provavelmente, a partir de constituintes da lamela média. Contudo, a presença de géis não foi um mecanismo eficiente para defender a variedade L62-96 contra a invasão da bactéria do RSD (Kao \& Damann, 1980). Estes autores examinaram muitas secções de colmos infectados, concluindo que a distribuição de Lxx não tinha sido retardada pela presença de géis. A L62-96 foi também estudada por Giglioti (1997). Este 
autor encontrou 58,99\% de vasos colonizados, dos quais apenas $16 \%$ estavam não funcionais. A bactéria estava presente; contudo, o transporte de água não foi completamente evitado nos vasos colonizados. Tal comportamento sugere que a desnsidade populacional de Lxx não foi suficiente para atuar como barreira física ao transporte de água pelo xilema nem para induzir a oclusão dos vasos do metaxilema produção de géis (Kao \& Damann, 1980) e gomas (Steindl, 1961; Weaver et al., 1 ؛ Enfim, tanto as bases bioquímicas e genéticas responsáveis pela resistência precisam ser estudadas, pois muito pouco se sabe sobre elas. O advento dos projetos Genoma da Cana e da Leifsoniz xyli subsp. xyli contribuirão para elucidar essa questão.

\subsection{Discussão geral}

Apesar dos primeiros danos causados pelo raquitismo-da-soqueira no Brasil terem sido observados em 1956 e, somente em 1978 foram publicados os resultados do primeiro experimento para avaliar a resistência de diferentes variedades de cana-deaçúcar cultivadas no Brasil. Esse experimento utilizou uma bomba a vácuo, desenvolvida para quantificar a diferença de vazão de água através dos colmos de parcelas sadias (tratadas termicamente) e inoculadas com caldo de plantas doentes para classificar as variedades quanto ao nível de resistência (Valarini, 1978). Esse método evoluiu (Douglas, 1981; Cruz, 1983), chegando até o método de coloração do xilema (Chagas, 1986), substituindo a bomba de vácuo pelo fluxo transpiratório da própria planta funcionando como "bomba de sucção”. Mais tarde, este método foi utilizado para avaliar a resistência de variedades comerciais em uso no Brasil (Iamauti, 1990; Chagas, 1996). Paralelamente, esforços foram dirigidos para avaliar a resistência ou tolerância de 
diferentes variedades através da comparação da produção entre parcelas sadias (tratadas termicamente) e inoculadas com caldo de plantas doentes (Matsuoka, 1980).

Tanto a avaliação da funcionalidade dos vasos como da diferença de produção são métodos indiretos da presença do patógeno. A primeira quantifica os efeitos da colonização dos vasos do xilema por Leifsonia xyli subsp. xyli na funcionalidade destes vasos e, conseqüentemente, no fluxo transpiratório da planta. A produção é um dos resultados da alteração fisiológica causada pela presença da bactéria nos vasos.

Por definição, resistência é a capacidade da planta em limitar o desenvolvimento do patógeno. Portanto, somente com o advento dos métodos que quantificam a densidade populacional de Lxx nos vasos ou a taxa de colonização destes pela bactéria, a resistência de variedades de cana-de-açúcar pôde ser avaliada de acordo com sua definição. Apesar do uso do TBIA ter sido sugerido para os Programas de Melhoramento Genético da Cana-de-açúcar do Brasil (Giglioti, 1997), o presente estudo relata a primeira avaliação da resistência de variedades brasileira com base na taxa de colonização do xilema dos colmos.

Nenhuma das variedades comerciais avaliadas pelo presente estudo apresentouse como resistente a Lxx. A taxa de colonização é relativamente alta, variando de 7 a 76\%, de acordo com o nível de resistência da variedade. Como a capacidade que cada variedade tem em limitar a taxa de colonização dos vasos do xilema é inversamente correlacionada com as perdas de produção causadas por Lxx (Davis et al, 1994; Miller et al., 1995) e medidas fitossanitárias tradicionais para seu controle não são 100\% eficientes, supõe-se que a bactéria esteja causando perdas nos canaviais brasileiros. Portanto, medidas devem ser tomadas para evitar tais perdas, como o uso de medidas 
fitossanitárias mais eficientes e esforços dos programas de melhoramento para a obtenção de variedades resistentes.

Como o uso de variedades resistentes é a medida mais racional e econômica de controle de doenças de plantas, TBIA tem sido utilizado com sucesso nos programas de melhoramento genético da cana-de-açúcar da Flórida e Luisiana (Comstock et al., 1993; Comstock et al., 1996ab; Davis et al., 1994; Miller et al., 1995). Na Flórida, o “screening” para a resistência ao RSD começa no terceiro ano de seleção, com aproximadamente 1.000 variedades, sendo 15\% delas classificadas como suscetíveis por apresentarem de 10 VC (Comstock et al., 1996ab). Análises de progênies têm demonstrado que 16,6 ou 9,3\% de variedades resistentes podem ser obtidas utilizando-se como limiar VC = 4 e 2, respectivamente (Miller et al., 1995). Como a herdabilidade da resistência ao RSD é alta (Miller et al., 1995), o incremento no uso de parentais resistentes combinado com “screening” para resistência nos estágios iniciais e finais do melhoramento genético têm permitido o desenvolvimento de variedades resistentes ao RSD. Esta estratégia está sendo conduzida com sucesso, permitindo o desenvolvimento de seis novas variedades com boa resistência ao RSD, somada a excelente potencial produtivo (Comstock, 1996a). Por que não fazer o mesmo no Brasil? Sugere-se então o uso do TBIA para buscar fontes de progenitores resistentes para aumentar a freqüência de progênies resistentes e para selecioná-las durante as etapas de desenvolvimento de uma nova variedade. 


\section{CONCLUSÕES}

Com base nos resultados obtidos pelo presente estudo, foram obtidas as seguintes conclusões:

- O método TBIA foi eficiente e eficaz para quantificar a taxa de colonização dos vasos do xilema de colmos de diferentes variedades de cana-de-açúcar por Leifsonia xyli subsp. xyli.

- O método de análise de agrupamento de Scott \& Knott (1974) aplicado aos dados gerados pelo TBIA permitiu a classificação das variedades em três níveis de resistência à colonização dos vasos do xilema dos colmos por Leifsonia xyli subsp. xyli: resistentes, intermediárias e suscetíveis.

- Com base na \%CV, as variedades CB47-355, CB41-76 e CB49-260 comportaram-se como resistente, intermediária e suscetível, respectivamente, constituindo-se em padrões para ensaios para avaliar a resistência de variedades à colonização dos vasos do xilema dos colmos por Leifsonia xyli subsp. xyli. 
- As variedades SP81-3250, RB865513, RB928064, RB825336, RB855002, RB925268, SP80-1842, SP80-1816, SP80-3280, RB867515, RB835054, SP83-2847 e RB85513 apresentaram resistência intermediária à colonização dos vasos do xilema dos colmos por Leifsonia xyli subsp. xyli.

- As variedades SP79-1011, SP86-155, SP79-2233, RB845210, RB855046, RB935621, RB935925, SP87-365, RB785158, RB806043, SP70-1143 E RB855595 apresentaram suscetibilidade à colonização por Leifsonia xyli subsp. xyli.

- Nenhuma das variedades comerciais avaliadas pelo presente estudo apresentou resistência à colonização dos vasos do xilema dos colmos por Leifsonia xyli subsp. xyli.

- Os programas de melhoramento genético da cana-de-açúcar no Brasil precisam dedicar procedimentos específicos para obtenção de novas variedades resistentes à colonização dos vasos do xilema dos colmos por Leifsonia xyli subsp. xyli. Neste particular, o método TBIA mostra-se bastante útil tanto para a escolha de progenitores resistentes para aumentar a porcentagem de progênies resistentes como para a seleção destas progênies ao longo do processo de obtenção de uma nova variedade.

- Como nenhuma variedade comercial avaliada apresentou resistência colonização dos vasos do xilema dos colmos por Leifsonia xyli subsp. xyli, os produtores não podem ser negligentes quanto ao emprego de medidas fitossanitárias eficientes para o controle do raquitismo-da-soqueira. 
- A premissa para uso do TBIA para identificação de genótipos de cana-deaçúcar resistentes a Leifsonia xyli subsp. xyli é que a população da bactéria disponível para o desenvolvimento do raquitismo-da-soqueira é o principal parâmetro epidemiológico que deve ser controlado para reduzir perdas. 


\section{REFERÊNCIAS BIBLIOGRAFICAS}

AUTREY, L.J.C.; DOOKUN, A.; SAUMTALLY, S.; DHAYAN, S.; SULLIVAN, S. Soil transmission of the ratoon stunting disease bacterium Clavibacter xyli subsp. xyli. Sugar Cane, v. 6, p. 5-6, 1991.

BAILEY, R.A. The systemic distribution and relative occurrence of bacteria in sugarcane varieties affected by ratoon stunting disease. Proceedings of the South African Technologists Association, v. 6, n. 9, p. 466-467, 1977.

BENDA, G.T.A. Studies on the with of a sorghum-sundangrass Irbid infected with ratoon stunting disease of sugarcane. Proceedingns of the American Phytopathological Society, v. 2, p. 65, 1975.

BETTI, J.A.; COSTA, A.S.; PARADELA, F.O.; SOAVE, J.; MATSUOKA, S. Descoloração vascular na região dos nós em capim elefante causada por várias espécies de bactérias. Fitopatologia Brasileira, v. 5, n. 2, p. 139-147, 1980. 
BREMER, G. Problems in breeding and cytology of sugarcane. Euphytica, v. 10, p. 5978, 1961.

CASTRO, P.R.C.; KLUGE, R.A.(Ed.). Ecofisiologia de culturas extrativas: cana-deaçúcar; seringueira; coqueiro; dendezeiro e oliveira. Cosmópolis: Editora Stoller do Brasil, 2001. 138 p.

CHAGAS, P.R.R. Método de coloração do xilema pela corrente transpiratória aplicado na determinação de infecção do raquitismo da soqueira em viveiros e cana-deaçúcar. Piracicaba, 1986. 123 p. Dissertação (Mestrado) - Escola Superior de Agricultura Luiz de Queiroz, Universidade de São Paulo.

CHAGAS, P.R.R. Raquitismo-da-soqueira: severidade dos sintomas do xilema e quantificação de danos agro-industriais. Piracicaba, 1996. 161 p. Tese (Doutorado) Escola Superior de Agricultura Luiz de Queiroz, Universidade de São Paulo.

CHAGAS, P.R.R; TOKESHI, H. Comparison between methods for diagnosis of ratoon stunting disease: I. Water flow, flow and staining and staining by transpiration. In: RAO, G.P.; GILLASPIE Jr, A.G.; UPADHYAYA, P.P.; BERGAMIN FILHO, A.; AGNIHOTRI, V.P.; CHEN, C.T. (Ed.). Current trends in sugarcane pathology. New Delhi: International Books \& Periodicals Supply Service, 1994. p.163-171. 
COMSTOCK, J.C.; SHINE JR., J.M.; PERDOMO, R. Ratoon stunting disease in Florida's non-hot-water treated sugarcane seedfields. Journal of the American Society of Sugar Cane Technologists, v. 13, p. 14-17, 1993.

COMSTOCK, J.C.; MILLER, J.D.; SHINE JR., J.M.; TAI, P.Y.P. Screening for resistance to ratoon stunting disease in Florida. Proceedings of the International Society of Sugar Cane Technologists, v. 22, p. 520-526, 1996a.

COMSTOCK, J.C.; SHINE JR., J.M.; DAVIS, M.J.; DEAN, J.L. Relationship between resitance to Clavibacter xyli subsp. Xyli colonization in sugarcane and spread of ratoon stunting disease in the field. Plant Disease, v. 80, n. 6, p. 704-708, 1996b.

CRUZ, M.M. Avaliação de resistência ao raquitismo da soqueira pela vazão de água em colmos de cana-de-açúcar e a interferência da escaldadura das folhas no método. Piracicaba, 1983. 51p. Dissertação (Mestrado) - Escola Superior de Agricultura Luiz de Queiroz, Universidade de São Paulo.

DAVIS, M.J. Direct - count techniques for enumerating Clavibacter xyli subsp. xyli wich causes ratoon stunting disease of sugarcane. Phytopathology, v.75, p. 12261231, 1985.

DAVIS, M.J. Taxonomy of plant-pathogenic coryneform bacteria. Annual Review of Phytopatology, v. 24, p. 115-140, 1986. 
DAVIS, M.J. Evaluation of Seletive media and immunoassays for detection of Xanthomonas albilineans, causal agent of sugarcane leaf scald disease. Plant Disease, v.78, n.1, p. 78-82. 1994.

DAVIS, M.J.; BAILEY, R.A. Ratoon Stunting. In: ROTT, P.; BAILEY, R.A.; COMSTOCK, J.C.; CROFT, B.J. \& SAUMTALLY, A.S. (Ed.). A guide to sugarcane diseases. Montpellier, CIRAD - ISSCT, 2000. p.49-54.

DAVIS, M.J.; DEAN, J.L; HARRISON, N.A. Distribution of Clavibacter xyli subsp. xyli in stalks of sugarcane cultivars differing in resistance to ratoon stunting disease. Plant Disease, v.72, p.443-448, 1988a.

DAVIS, M.J.; DEAN J.L; HARRISON, N.A. Quantitative variability of Clavibacter xyli subsp. xyli populations in sugarcane cultivars differing in resistance to ratoon stunting disease. Phytopathology, v.78, p. 462-468, 1988b.

DAVIS, M.J.; DEAN J.L; MILLER, J.D.; SHINE JR, J.M. A method to screen for resistance to ratoon stunting disease of sugarcane. Sugar Cane, v. 6. p. 9-16, 1994. 
DAVIS, M. J.; GILLASPIE, JR., A.G.; HARRIS, R.W.; LAWSON, R.H. Ratoon stunting disease of sugarcane. Isolation of the causal bacterium. Science, v.240, p. $1365-1367,1980$.

DAVIS, M.J.; GILLASPIE JR, A.G.; VIDAVER, A.K.; HARRIS, R.H. Clavibacter: A new genus containing some phytopathogenic coryneform bacteria, including Clavibacter xyli subsp. xyli sp. Nov., subsp. nov. and Clavbibacter xyli subsp. cynodontis subsp. nov., pathogens that cause ratoon stunting disease of sugarcane and Bermudagrass stunting disease. International Journal of Systematic Bacteriology, v. 34, n. 2, p.107-117. 1984.

DAMANN JR., K.E. Effect of sugarcane cultivar susceptibility on spread of ratoon stunting disease by the mechanical harvester. Plant Disease, v. 76, p. 1148-1149, 1992.

D’HONT, A.; RAO, P.; FELDMANN, P.; GRIVET, L.; ISLAN-FARIDI, N.; BERDING, N.; GLASZMANN, J.C..Identification and characterization of intergeneric hybrids, Saccharum officinarum x Erianthus araundinaceus, with molecular markers and in situ hybridization. Theoretical and Applied Genetics, v. 91, p. 320-326, 1995. 
DOUGLAS, R.A. Correlação entre vazão de água e resistência ao raquitismo da soqueira em cana-de-açúcar. Piracicaba, 1981. 57p. Dissertação (Mestrado) - Escola Superior de Agricultura Luiz de Queiroz, Universidade de São Paulo.

DUNCAN, D.B. Multiple range and multiple F tests. Biometrics, v. 21, p. 11-42, 1955.

EKSOMTRAMAGE, T.; PAULET, F.; NOYER, J.L.; FELDMANN, P.; GLASZMANN, J.C. Utility of isoenzymes in sugarcane breeding. Sugar Cane, v. 3, p. 14-21, 1992.

FEGAN, M.; CROFT, B.J.; TEAKLE, D.S.; HAYWARD, A.C.; SMITH, G.R. Sensitive and specific detection of Clavibacter xyli subsp. xyli, causal agent of ratoon stunting disease of sugarcane, with a polymerase chain reaction-based assay. Plant Pathology, v. 47, p. 495-504, 1998.

GARCIA, A.F.G., MATSUOKA, S., SOUZA JR., C.L., SOUZA, A.P., LIMA, M.L.A. Diversidade e base genética das variedades de cana-de-açúcar (Saccharum L. Spp.) brasileiras. In: CONGRESSO BRASILEIRO DE GENÉTICA, 45., Gramado, 1999. Anais. Gramado: SBG, 1999. p. 686.

GIGLIOTI, E.A. Método Conciliado para avaliar os efeitos da colonização de colmos de cana-de-açúcar por Clavibacter xyli subsp. xyli. Piracicaba, 1997. 134 p. Tese (Doutorado). Escola Superior de Agricultura Luiz de Queiroz, Universidade de São Paulo. 
GILLASPIE JR., A.G., DAVIS, M.J. Ratoon stunting disease of sugarcane. In: MUKHOPADHYAY, A. N.; KAMAR, J.; CHAUBE, H.S.; SING, U.S. (Ed.). Plant diseases of international importance disease of sugar, forest, and plantation crops. Englewood Cliffs: New Jersey, Prentice Hall, 1992. v. 4, p. 41-61.

GILLASPIE JR., A.G.; TEAKLE, D.S. Ratoon stunting disease. In: RICAUD, C.; EGAN, B.T.; GILlASPIE JR., A.G.; HUGHES, C.G. (Ed.). Diseases of sugarcane: major diseases. Amsterdam: Elsevier, 1989. p. 59-80.

GILLASPIE JR., A.G.,; DAVIS, R.E.; WORLEY, J.F. Diagnosis of ratoon stunting disease based on the presence of a specific microorganism. Plant Disease Reporter, v. 57, n. 12, p. 987-990, 1973.

GILLASPIE JR., A.G.; FLAX, G.; KOIKE, H. Relationship between numbers of diagnostic bacteria and injury by ratoon stunting disease in sugarcane. Plant Disease Reporter, v. 60, n. 7, p.573-575, 1976.

GILLASPIE JR., A. G.; IRVINE, J.E.; STEERE, R.L. Ratoon Stunting disease virus assay technique and partial purification. Phytopathology, v. 56, p. 1426-1427, 1966. 
GHELLER, A.C.A. Avaliação da eficiência de dois sistemas de tratamento térmico para inativação da bactéria causadora do raquitismo da soqueira em cana-de-açúcar. Piracicaba, 1986. 99 p. Dissertação ( Mestrado) - Escola Superior de Agricultura Luiz de Queiroz, Universidade de São Paulo.

GLASZMANN, J.C.; NOYER, J.L.; FAUTRET, A.; FELDMANN, P.; LANAUD, C..Biochemical genetic markers in sugarcane. Theoretical and Applied Genetics, v. 78, p. 537-543, 1989.

HARRISON, N. A.; DAVIS, M. J. Colonization of vascular tissues by Clavibacter xyli subsp. xyli in stalks of sugarcane cultivars differing in susceptibility to ratoon stunting disease. Phytopathology, v.78, n.6, p. 722-727, 1988.

HUGHES, C.G. The economic importante of ratoon stunting disease. Proceedings of the International Society of Sugar Cane Technologists, v. 15, n. 1, p. 213-217, 1974.

IAMAUTI, M.T. Comparação de métodos para diagnose do raquitismo da soqueira da cana-de-açúcar (Clavibacter xyli subsp. xyli) e aplicação na seleção de variedades resistentes. Piracicaba, 1990. 133 p. Dissertação ( Mestrado) - Escola Superior de Agricultura Luiz de Queiroz, Universidade de São Paulo. 
IAMAUTI, M.T.; TOKESHI, H. Comparison between methods for diagnosis of ratoon stunting disease (Clavibacter xyli subsp. xyli): II. Staining by transpiration method, observation of bacterium in contrast phase microscope, alkaline-induced metaxylem autofluorescence. In: RAO, GP.; GILLASPIE JR., A.G. ; UPADHYAYA, P.P; BERGAMIN FILHO, A.; AGNIHOTRI, V.P.; CHEN, C.T. (Ed.). Current trends in sugarcane pathology. New Delhi: International Books \& Periodicals Supply Service, 1994. p. 173-184.

JANNOO, N.; GRIVET, L.; SEGUIN, M.; PAULET, F.; DOMAINGUE, R.; RAO, P.S.; DOOKUM, A.; D’HONT, A.; GLASZMANN, J.C. .Molecular investigation of the genetics base sugarcane cultivars. Theoretical and Applied Genetics, v. 99, p. 171-184, 1999.

KAO, J.; DAMANN JR., K.E. In situ localization and morphology of the bacterium associated with ratoon stunting disease of sugarcane. Canadian Journal of Botany, v. 58, n. 3, p. 310-315, 1980.

KOIKE, H. Interaction between mosaic and ratoon stunting disease on two commercial sugarcane clones. Sugarcane Pathologist's Newsletter, v. 29, p. 44-48, 1982.

LEE, T. S. G. Produção de mudas sadias de cana-de-açúcar através de cultura de tecidos. Álcool e Açúcar, v. 45, p. 20-29, 1988. 
LIMA, M.L.A.; GARCIA, A.A.F.; OLIVEIRA, K.; MATSUOKA, S.; ARIZONO, H.; SOUZA JR., C.L; SOUZA, A.P.de. Analysis of genetic similarity detected by AFLP and coefficient of parentage among genotypes of sugarcane (Saccharum spp). Theoretical and Applied Genetics, v. 104, p. 30-38, 2002.

LOPEZ-ROSA, J. H.; ADSUAR, J. Effect of ratoon stunting disease on yield of some sugarcane varietis in Puerto Rico. Journal of Agricultural of University of Puerto Rico, v. 54, p. 149-60, 1970.

LUI, L.J., CORTÉS-MONLLOR, A.; BENDA, G.T.A.; MARAMOROSCH, K.; HIRUMI, H.; PÉREZ, J.E.; BIRD, J. Isolation of na organism resembling Xanthomonas vasculorum from sugarcane affected by ratoon stunting disease. Proceedings of the International Society of Sugar Cane Technologists, v. 15, n. 1, p. 234-240, 1974.

MARAMOROSCH, K.; PLAVSIC-BANJAC, B.; BIRD, J.; LIU, L.J. Electron microscopy of ratoon stunted sugar cane: microorganisms in xylem. Phytopathologische Zeitscript, v. 77, p. 270-273, 1973.

MATSUOKA, S. Incidência do vírus do raquitismo da soqueira em canas provenientes de material propagativo tratado termicamente. Campinas: Instituto Agronômico, 1971. 2p. 
MATSUOKA, S. Ratoon Stunting disease diagnosis with elephant-grass as a indicator plant. Sugarcane Pathologist’s Newletter, v. 8, p. 10-11, 1972.

MATSUOKA, S. Recuperação da produtividade de variedades de cana-de-açúcar pelo tratamento térmico de toletes. Brasil Açucareiro, v.87, n. 5, p. 20-24, 1976.

MATSUOKA, S. Microplots for screencing sugarcane varieties for tolerance to ratoon stunting disease. Proceedings of the International Society of Sugar Cane Technologists, v. 17, p. 1628-1638, 1980.

MATSUOKA, S. Longevidade do efeito do tratamento térmico em canas infectadas pelo raquitismo da soqueira. In: CONGRESSO NACIONAL DA SOCIEDADE DOS TÉCNICOS AÇUCAREIROS DO BRASIL, Piracicaba, 1984. Anais. Piracicaba: STAB, 1984. v.3, p. 244-249.

MATSUOKA, S. The contribuiion of man-made varieties to the sugar cane industry in São Paulo. Ciência e Cultura, v. 43, p. 282-289, 1991.

MATSUOKA, S. Ter ou não ter doença, eis a questão.Summa Phytopathologica, v. 19, n. 34, p. 145-151, 1993. 
MATSUOKA, S.; GARCIA A.A.F.; ARIZONO, H.. Melhoramento da cana-de-açúcar. In: BORÉM, A. (Ed.). Melhoramento de espécies cultivadas. 2.ed. Viçosa: Editora UFV, 1999. p.205-251.

MILLER, J.D.; DAVIS, M.J.; DEAN, J.L.; SHINE JR, J.M. Heritability of resistance of ratoon stunting disease in Sugarcane. Sugar Cane, v. 1, p. 3-8, 1995.

MIOCQUE, J.Y.J.; MACHADO JR., G.R. Review of sugarcane varieties and breeding in Brazil. Sugarcane Journal, v. 23, p.9-13, 1977.

PAN, Y.B.; GRISHAM, M.P.; BURNER, D.M.; DAMANN, JR.,K.E.; WEI, Q. A polymerase chain reaction protocol for the detection of Clavibacter xyli subsp. xyly, the causal bacterium of sugarcane ratoon stunting disease. Plant Disease, v.82, p. 258-290, 1998.

PLAVSIC-BANJAC, B.; MARAMOROSCH, K. Electron microscopy of the xylem of ratoon stunted sugarcane. Phytopathology, v. 65, n. 5, p. 498-499, 1972.

RICAUD, C. Problems in the diagnosis of ratoon stunting disease. Proceedings of the International Society of Sugar Cane Technologists, v. 15, p. 241-248, 1974. 
RICAUD, C.; RYAN, C.C. Leaf scald. In: RICAUD, C.; EGAN, B.T.; GILLASPIE JR., A.G.; HUGHES, C.G. (Ed.). Diseases of sugarcane: major diseases. Amsterdam: Elsevier Science, 1989. p. 39-58.

ROBINSON, R.A. Host manegment in crop pathosystems. New York: Macmillan, 1987. 263 p.

RUAS, D.G.; MATSUOKA, S.; GHELLER, A.C.A. Situação do uso do equipamento de tratamento térmico no centro-sul na safra 1985/86. Brasil Açucareiro, v.105, n. 1, p. 13-16, 1987.

SANGUINO, A. Principais moléstias da cana-de-açúcar. In: PARANHOS, S.B. Canade-açúcar: cultivo e utilização. Campinas: Fundação Cargill, 1987. Cap. 6, p. 741757.

SANGUINO, A. Binômio tempo X temperatura no controle do raquitismo da soqueira (RSD) da cana-de-açúcar, pelo processo de termoterapia de gemas isoladas. Cadernos Copersucar, v.25, p. 1-5, 1989.

SCOTT, A.J.; KNOTT, M. A cluster analysis method for grouping means in the analysis of variance. Biometrics, v. 30, p. 507-512, 1974.

SIVANESAN, A.; WALLER, J.M. Sugarcane disease. Commonwealth Mycological Institute, Phytopathological Paper n. 29, p. 73, 1986. 
SORDI, R. A. Escaldadura das folhas da cana-de-açúcar: crescimento in vitro do agente causal (Xanthomonas albilineans), diagnose por planta teste e cura por termoterapia in vitro e cultura de ápice meristemático. Piracicaba, 1986. 161 p. Disseertação (Mestrado) - Escola Superior de Agricultura Luiz de Queiroz, Universidade de São Paulo.

SREENIVASAN, T.V.; AHLOOWALIA, B.S. AND HEINZ, D.J..Cytogenetics. In: HEINZ, D.J. (Ed.). Sugarcane improvement through breeding. Amsterdam: Elsevier, 1987. p. 211-253.

STEINDL, D.R.L. Q. 28 disease. Cane Grow, v. 12, n. 4, p. 191-193, 1949.

STEINDL, D.R.L. Ratoon stunting disease. In: MARTIN, J.P.; ABBOTT, E.V.; HUGHES, C.G. (Ed.). Sugarcane diseases of the world. Amsterdam: Elsevier, 1961. v.1, p. 433-459.

TEAKLE, D.S.; SMITH, P.M.; STEINDL, D.R.L. Association of a small coryneform bacterium with the ratoon stunting disease of sugarcane. Australian Journal of Agricultural Research, v. 24, p. 869-874, 1973. 
TEAKLE, D.S.; SMITH, P.M.; STEINDL, D.R.L. Ratoon stunting disease of sugarcane: possible correlation of resistance with vascular anatomy. Phytopathology, v. 65, n. 2, p. 138-141, 1975 a.

TEAKLE, D.S.; APPLETON, J.M.; STEINDL, D.R.L. An anatomical basis for resistance of sugarcane to ratoon stunting disease. Physiological Plant Pathology, v. 12, p. 83-91, 1978.

TEAKLE, D.S.; SMITH, P.M.; HAYWARD, A.C.; STEINDL, D.R.L. Diagnosis of R.S.D. by electron microscopy of sugar-cane tissue diffusates. Proceedings Queensland Society of Sugarcane Technologists, v. 42, p. 115-116, 1975 b.

TOKESHI, H. Cana-de-açúcar (Saccharum officinarum L.). Controle de doenças. In: VALE, F.X.R; ZAMBOLIM, L. (Ed.). Controle de doenças de plantas. Viçosa: UFV, 1997a. v. 2, p.657-751.

TOKESHI, H. Doenças da cana-de-açúcar. In: KIMATI, H.; AMORIM, L.; BERGAMIN FILHO, A.; CAMARGO, L.E.A.; REZENDE, J.A.M. (Ed.). Manual de fitopatologia: doenças das plantas cultivadas. São Paulo: Editora Ceres, v. 2, p. 207-225, $1997 b$. 
TOKESHI, H.; SANGUINO, A.; AKIBA, F. Xanthomonas albilineans, provável agente causal de raquitismo da soqueira e escaldadura da cana-de-açúcar. Brasil Açucareiro, v. 84, n. 6, p. 28-40, 1974.

TOKESHI, M.; GHELLER, A.C.A.; SORDI, R.A.; MASUDA, Y.; MATSUOKA, S. Nova unidade de tratamento térmico de toletes de cana-de-açúcar para controle do raquitismo da soqueira (RSD). Summa Phytopathologica, v. 9, p. 59-61, 1983.

VALARINI, P.J. Avaliação da resistência ao raquitismo da soqueira pelo método da vazão de água em colmos de cana-de-açúcar. Piracicaba, 1978. 78p. Dissertação (Mestrado) - Escola Superior de Agricultura Luiz de Queiroz, Universidade de São Paulo.

VALARINI, P.J.; TOKESHI, H. Factors that interfere in evaluation of ratoon stunting disease resistance by water flow in sugarcane stalks. Summa Phytopathologica, v.7, n. 3/4, p. 51-56, 1981.

VANDERPLANDK, J.E. Disease resistance in plants. 2. ed. Orlando: Academic Press. 1984. p.194.

VEIGA, F.M. Nota sobre o raquitismo das socas em campos. Brasil Açucareiro, v. 47, n.1, p. 81-83, 1956. 
WEAVER, L.; TEAKLE, D.S.; HAYWARD, A.C. Ultrastructural studies on the bacterium on associated with the ratoon stunting disease of sugarcane. Australian Journal of Agricultural Research, v. 28, p. 843-852, 1977.

WEHLBURG, C. Ratoon stunting disease in Cuba. Sugar Journal, v. 51, n.3, p. 27-29, 1956.

YOUNG, J.M.; TOKIKAWA, Y.; GARDAN, L.; STEAD, D.E.Changing concepts in the taxonomy of plant pathogenic bacteria. Annual Review of Phytopathology, v. 30, p. 67-105, 1992. 